\title{
COMPLEX PROBABILITY THEORY AND PROGNOSTIC
}

\author{
Abdo Abou Jaoude \\ Department of Mathematics and Statistics, \\ Faculty of Natural and Applied Sciences, Notre Dame University, Zouk Mosbeh, Lebanon
}

Received 2013-08-27; Revised 2013-10-06; Accepted 2013-10-09

\begin{abstract}
The Kolmogorov's system of axioms can be extended to encompass the imaginary set of numbers and this by adding to the original five axioms an additional three axioms. Hence, any experiment can thus be executed in what is now the complex set $\mathrm{C}$ (Real set $\mathrm{R}$ with real probability + Imaginary set $\mathrm{M}$ with imaginary probability). The objective here is to evaluate the complex probabilities by considering supplementary new imaginary dimensions to the event occurring in the "real" laboratory. Whatever the probability distribution of the input random variable in $\mathrm{R}$ is, the corresponding probability in the whole set $\mathrm{C}$ is always one, so the outcome of the random experiment in $\mathrm{C}$ can be predicted totally. The result indicates that chance and luck in $\mathrm{R}$ is replaced now by total determinism in $\mathrm{C}$. This new complex probability model will be applied to the concepts of degradation and the Remaining Useful Lifetime (RUL), thus to the field of prognostic.
\end{abstract}

Keywords: Complex Probability, Probability Distributions, Prognostic, Degradation, Lifetime

\section{INTRODUCTION}

Abou Jaoude et al. (2010); Abou Jaoude (2013; 2005; 2007); Bell (1992); Benton (1996); Boursin (1986); Chen et al. (1997); Cheney and Kincaid (2004); Dacunha-Castelle (1999); Dalmédico Dahan et al. (1992); Dalmedico Dahan and Peiffer (1986); Ekeland (1991); Feller (1968); Finney et al. (2004); Gentle (2003); Gerald and Wheatley (1999); Gleick (1997); Greene (2000; 2004) firstly, the Extended Kolmogorov's Axioms (EKA for short) paradigm can be illustrated by the following figure (Fig. 1).

In engineering systems, the remaining useful lifetime prediction is related deeply to many factors that generally have a chaotic behavior which decreases the degree of our knowledge of the system.

As the Degree of Our Knowledge (DOK for short) in the real universe $\mathrm{R}$ is unfortunately incomplete, the extension to the complex universe $\mathrm{C}$ includes the contributions of both the real universe $R$ and the imaginary universe $\mathrm{M}$. Consequently, this will result in a complete and perfect degree of knowledge in $\mathrm{C}=\mathrm{R}+\mathrm{M}$ $(\mathrm{Pc}=1)$. In fact, in order to have a certain prediction of any event it is necessary to work in the complex universe $\mathrm{C}$ in which the chaotic factor is quantified and subtracted from the Degree Of Knowledge to lead to a probability in $\mathrm{C}$ equal to one $\left(\mathrm{Pc}^{2}=\mathrm{DOK}-\mathrm{Chf}=1\right)$. Thus, the study in the complex universe results in replacing the phenomena that used to be random in $\mathrm{R}$ by deterministic and totally predictable ones in C.

This hypothesis is verified in a previous study and paper by the mean of many examples encompassing both discrete and continuous distributions.

From the Extended Kolmogorov's Axioms (EKA), we can deduce that if we add to an event probability in the real set $\mathrm{R}$ the imaginary part $\mathrm{M}$ (like the lifetime variables) then we can predict the exact probability of the remaining lifetime with certainty in $\mathrm{C}(\mathrm{Pc}=1)$.

We can apply this idea to prognostic analysis through the degradation evolution of a system. As a matter of fact, prognostic analysis consists in the prediction of the remaining useful lifetime of a system at any instant $t_{0}$ and during the system functioning.

Let us consider a degradation trajectory $\mathrm{D}(\mathrm{t})$ of a system where a specific instant $t_{0}$ is studied. The instant $t_{0}$ means here the time or age that can be measured also by the cycle number $\mathrm{N}$.

Referring to the figure below (Fig. 2), the previous statement means that at the system age $t_{0}$, the prognostic study must give the prediction of the failure instant $t_{N}$. Therefore, the RUL predicted here at instant $t_{0}$ is the following quantity: RUL $\left(\mathrm{t}_{0}\right)=\mathrm{t}_{\mathrm{N}}-\mathrm{t}_{0}$. 


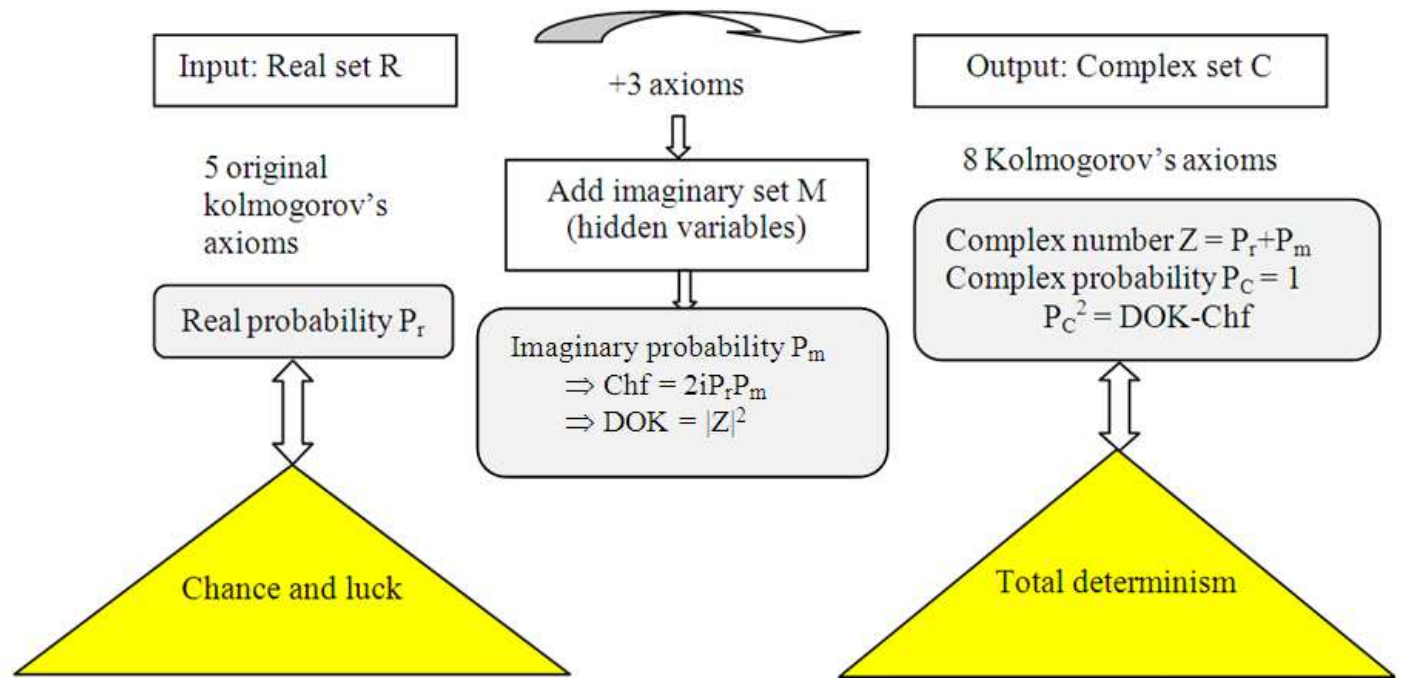

Fig. 1. EKA paradigm

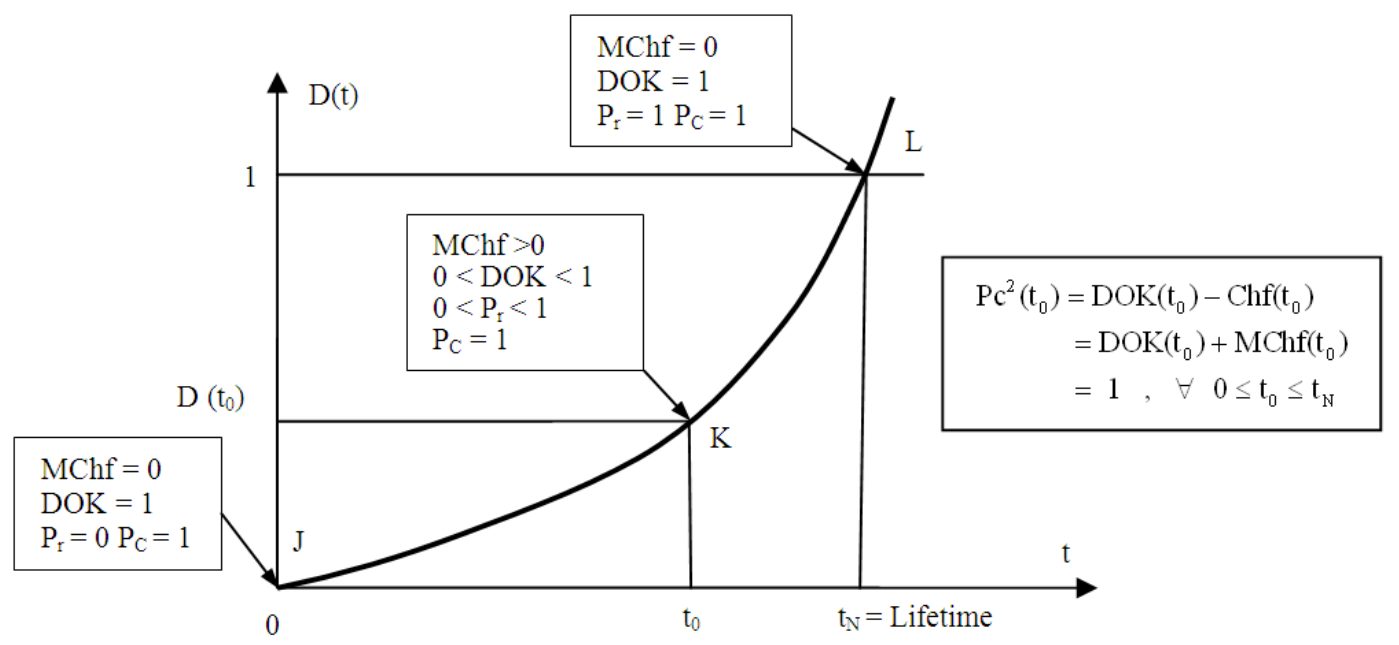

Fig. 2. EKA and the prognostic of degradation

In fact, at the beginning $\left(t_{0}=0\right.$ ) (point $J$ ), the failure probability $\mathrm{P}_{\mathrm{r}}=0$ and the chaotic factor in our prediction is zero $(\mathrm{Chf}=0)$. Therefore, $\operatorname{RUL}\left(\mathrm{t}_{0}=0\right)=\mathrm{t}_{\mathrm{N}^{-}} \mathrm{t}_{0}=\mathrm{t}_{\mathrm{N}}$.

If $t_{0}=t_{N}$ (point L) then the $\operatorname{RUL}\left(t_{N}\right)=t_{N}-t_{N}=0$ and the failure probability is one $\left(\mathrm{P}_{\mathrm{r}}=1\right)$.

If not (i.e., $0<\mathrm{t}_{0}<\mathrm{t}_{\mathrm{N}}$ ) (point $\mathrm{K}$ ), the probability of the occurrence of this instant and the prediction probability of RUL are both less than one (not certain) due to nonzero chaotic factors. The degree of our knowledge is consequently less than 1 . Thus, by applying here the EKA method, we can determine the system RUL with certainty in $\mathrm{C}=\mathrm{R}+\mathrm{M}$ where $\mathrm{Pc}=1$ always.
Furthermore, we need in our current study the absolute value of the chaotic factor that will give us the magnitude of the chaotic and random effects on the studied system. This new term will be denoted accordingly MChf or Magnitude of the Chaotic Factor. Hence, we can deduce the following:

$$
\begin{aligned}
& \operatorname{MChf}\left(\mathrm{t}_{0}\right)=\left|\operatorname{Chf}\left(\mathrm{t}_{0}\right)\right| \geq 0 \text { and } \\
& \operatorname{Pc}^{2}\left(\mathrm{t}_{0}\right)=\operatorname{DOK}\left(\mathrm{t}_{0}\right)-\operatorname{Chf}\left(\mathrm{t}_{0}\right)=\operatorname{DOK}\left(\mathrm{t}_{0}\right)+\left|\operatorname{Chf}\left(\mathrm{t}_{0}\right)\right|, \\
& \text { since }-0.5 \leq \operatorname{Chf}\left(\mathrm{t}_{0}\right) \leq 0 \\
& =\operatorname{DOK}\left(\mathrm{t}_{0}\right)+\operatorname{MChf}\left(\mathrm{t}_{0}\right)=1, \quad \forall 0 \leq \mathrm{t}_{0} \leq \mathrm{t}_{\mathrm{N}} \\
& \Leftrightarrow 0 \leq \operatorname{MChf}\left(\mathrm{t}_{0}\right) \leq 0.5 \quad \text { where } 0.5 \leq \operatorname{DOK}\left(\mathrm{t}_{0}\right) \leq 1
\end{aligned}
$$


Moreover, we can define two complementary events $\mathrm{E}$ and $\overline{\mathrm{E}}$ with their respective probabilities:

$$
\mathrm{P}_{\mathrm{rob}}(\mathrm{E})=\mathrm{p} \text { and } \mathrm{P}_{\mathrm{rob}}(\overline{\mathrm{E}})=\mathrm{q}=1-\mathrm{p}
$$

Then $P_{\text {rob }}(E)$ in terms of the instant $t_{0}$ is given by: $P_{\text {rob }}$ (E) $=\mathrm{P}_{\mathrm{r}}=\mathrm{P}_{\text {rob }}\left(\mathrm{t} \leq \mathrm{t}_{0}\right)=\mathrm{F}\left(\mathrm{t}_{0}\right)$ where $\mathrm{F}$ is the cumulative probability distribution function of the random variable $t$.

Since $\mathrm{P}_{\text {rob }}(\mathrm{E})+\mathrm{P}_{\text {rob }}(\overline{\mathrm{E}})=1$, therefore, $\mathrm{P}_{\text {rob }}(\overline{\mathrm{E}})=1$ $\mathrm{P}_{\text {rob }}(\mathrm{E})=1-\mathrm{P}_{\mathrm{r}}=1-\mathrm{P}_{\text {rob }}\left(\mathrm{t} \leq \mathrm{t}_{0}\right)=\mathrm{P}_{\text {rob }}\left(\mathrm{t}>\mathrm{t}_{0}\right)$.

Let us define the two particular instants: $t_{0}=0$ assumed as the initial time of functioning (raw state) corresponding to $\mathrm{D}=\mathrm{D}_{0}=0$ and $\mathrm{t}_{\mathrm{N}}=$ the failure instant (wear out state) corresponding to the degradation $\mathrm{D}=1$.

The boundary conditions are.

For $\mathrm{t}_{0}=0$ then $\mathrm{D}=\mathrm{D}_{0}$ (initial damage that may be zero or not) and $\mathrm{F}\left(\mathrm{t}_{0}\right)=\mathrm{P}_{\text {rob }}(\mathrm{t} \leq 0)=0$.

For $\mathrm{t}_{0}=\mathrm{t}_{\mathrm{N}}$ then $\mathrm{D}=1$ and $\mathrm{F}\left(\mathrm{t}_{0}\right)=\mathrm{F}\left(\mathrm{t}_{\mathrm{N}}\right)=\mathrm{P}_{\text {rob }}\left(\mathrm{t} \leq \mathrm{t}_{\mathrm{N}}\right)=1$.

Also $F\left(t_{0}\right)$ is a non-decreasing function that varies between 0 and 1 . In fact, $F\left(t_{0}\right)$ is a cumulative function (Fig. 3). In addition, since RUL( $\left.t_{0}\right)=t_{N}-t_{0}$ and $0 \leq t_{0} \leq t_{N}$ then $\operatorname{RUL}\left(\mathrm{t}_{0}\right)$ is a non-increasing remaining useful lifetime function (Fig. 4).

Referring to Fig. 5 below, we can infer the following:

The complex probability $\mathrm{Z}\left(\mathrm{t}_{0}\right)=\mathrm{P}_{\mathrm{r}}\left(\mathrm{t}_{0}\right)+\mathrm{P}_{\mathrm{m}}\left(\mathrm{t}_{0}\right)=$ $\mathrm{P}_{\mathrm{r}}\left(\mathrm{t}_{0}\right)+\mathrm{i}\left[1-\mathrm{P}_{\mathrm{r}}\left(\mathrm{t}_{0}\right)\right]$.

The square of the norm of $\mathrm{Z}\left(\mathrm{t}_{0}\right)$ is:

$$
\begin{aligned}
& \left|\mathrm{Z}\left(\mathrm{t}_{0}\right)\right|^{2}=\operatorname{DOK}\left(\mathrm{t}_{0}\right)=1+2 \mathrm{iP}_{\mathrm{r}}\left(\mathrm{t}_{0}\right) \mathrm{P}_{\mathrm{m}}\left(\mathrm{t}_{0}\right) \\
& =1-2 \mathrm{P}_{\mathrm{r}}\left(\mathrm{t}_{0}\right)\left[1-\mathrm{P}_{\mathrm{r}}\left(\mathrm{t}_{0}\right)\right]=1-2 \mathrm{P}_{\mathrm{r}}\left(\mathrm{t}_{0}\right)+2 \mathrm{P}_{\mathrm{r}}^{2}\left(\mathrm{t}_{0}\right)
\end{aligned}
$$

The Chaotic Factor and the Magnitude of the Chaotic Factor are:

$\operatorname{Chf}\left(\mathrm{t}_{0}\right)=-2 \mathrm{P}_{\mathrm{r}}\left(\mathrm{t}_{0}\right)\left[1-\mathrm{P}_{\mathrm{r}}\left(\mathrm{t}_{0}\right)\right]=-2 \mathrm{P}_{\mathrm{r}}\left(\mathrm{t}_{0}\right)+2 \mathrm{P}_{\mathrm{r}}^{2}\left(\mathrm{t}_{0}\right)$ is null when $\mathrm{P}_{\mathrm{r}}\left(\mathrm{t}_{0}\right)=\mathrm{P}_{\mathrm{r}}(0)=0$ (point $\mathrm{J}$ ) or when $\mathrm{P}_{\mathrm{r}}\left(\mathrm{t}_{0}\right)=\mathrm{P}_{\mathrm{r}}\left(\mathrm{t}_{\mathrm{N}}\right)=1$ (point L) and $\operatorname{MChf}\left(\mathrm{t}_{0}\right)=\left|\operatorname{Chf}\left(\mathrm{t}_{0}\right)\right|=2 \mathrm{P}_{\mathrm{r}}\left(\mathrm{t}_{0}\right)\left[1-\mathrm{P}_{\mathrm{r}}\left(\mathrm{t}_{0}\right)\right]=$ $2 \mathrm{P}_{\mathrm{r}}\left(\mathrm{t}_{0}\right)-2 \mathrm{P}_{\mathrm{r}}^{2}\left(\mathrm{t}_{0}\right)$ is null when $\mathrm{P}_{\mathrm{r}}\left(\mathrm{t}_{0}\right)=\mathrm{P}_{\mathrm{r}}(0)=0$ (point $\mathrm{J}$ ) or when $\mathrm{P}_{\mathrm{r}}\left(\mathrm{t}_{0}\right)=\mathrm{P}_{\mathrm{r}}\left(\mathrm{t}_{\mathrm{N}}\right)=1$ (point $\left.\mathrm{L}\right)$

At any instant $t_{0}$ (point $\mathrm{K}$ ), the probability expressed in the complex set $\mathrm{C}$ is:

$$
\operatorname{Pc}\left(\mathrm{t}_{0}\right)=\mathrm{P}_{\mathrm{r}}\left(\mathrm{t}_{0}\right)+\mathrm{P}_{\mathrm{m}}\left(\mathrm{t}_{0}\right) / \mathrm{i}=\mathrm{P}_{\mathrm{r}}\left(\mathrm{t}_{0}\right)+\left[1-\mathrm{P}_{\mathrm{r}}\left(\mathrm{t}_{0}\right)\right]=1 \text { always. }
$$

Hence, the prediction of $\operatorname{RUL}\left(\mathrm{t}_{0}\right)$ of the system degradation in $\mathrm{C}$ is permanently certain.

Let us consider thereafter many probability distributions to model the function $\mathrm{F}\left(\mathrm{t}_{0}\right)$.

\section{APPLICATION TO DIFFERENT PROBABILITY DISTRIBUTIONS}

2.1. The Uniform Probability Distribution (Guillen, 1995; Gullberg, 1997; Kuhn, 1996; Liu, 2001; Mandelbrot, 1997; Montgomery and Runger, 2005; Mũller, 2005; Orluc and Poirier, 2005; Poincaré, 1968; Prigogine, 1997; Prigogine and Stengers, 1992; Robert and Casella, 2010; Science et Vie, 1999; Srinivasan and Mehata, 1978; Stewart, 1996; 2002; Van Kampen, 2007; Walpole, 2002; Ducrocq and Warusfel, 2004; Weinberg, 1992)

With a probability density function:

$$
f(t)=\frac{d F(t)}{d t}=\left\{\begin{array}{cc}
\frac{1}{b-a} & \text { if } \quad a \leq t \leq b \\
0 & \text { elsewhere }
\end{array}\right.
$$

and a cumulative distribution function:

$$
F\left(t_{0}\right)=P_{\text {rob }}\left(t \leq t_{0}\right)=\int_{-\infty}^{t_{0}} f(t) d t=\int_{a}^{t_{0}} f(t) d t=\left\{\begin{array}{ccc}
\frac{t_{0}-a}{b-a} & \text { if } \quad a \leq t_{0} \leq b \\
0 & \text { elsewhere }
\end{array}\right.
$$

With the two boundaries $\mathrm{a}=0$ and $\mathrm{b}=\mathrm{t}_{\mathrm{N}}$ then:

$$
\mathrm{F}\left(\mathrm{t}_{0}\right)=\frac{\mathrm{t}_{0}-0}{\mathrm{t}_{\mathrm{N}}-0}=\frac{\mathrm{t}_{0}}{\mathrm{t}_{\mathrm{N}}} \quad \text { if } \quad 0 \leq \mathrm{t}_{0} \leq \mathrm{t}_{\mathrm{N}}
$$

We have taken the domain for the uniform variable $\mathrm{t}_{0}=\left[0, \mathrm{t}_{\mathrm{N}}=1000\right]$ and $\mathrm{dt}_{0}=0.1$ then:

$$
\mathrm{F}\left(\mathrm{t}_{0}\right)=\frac{\mathrm{t}_{0}}{1000} \quad \text { if } \quad 0 \leq \mathrm{t}_{0} \leq 1000
$$

\subsubsection{The Real Probability $P_{r}$ :}

$$
\mathrm{P}_{\mathrm{r}}\left(\mathrm{t}_{0}\right)=\mathrm{F}\left(\mathrm{t}_{0}\right)=\frac{\mathrm{t}_{0}}{\mathrm{t}_{\mathrm{N}}} \quad \text { if } \quad 0 \leq \mathrm{t}_{0} \leq \mathrm{t}_{\mathrm{N}}=1000
$$

We note that $\mathrm{P}_{\mathrm{r}}\left(\mathrm{t}_{0}\right)$ is a non-decreasing function.

\subsubsection{The Complementary Probability $P_{m} / \mathbf{i}$ :}

$\mathrm{P}_{\mathrm{m}}\left(\mathrm{t}_{0}\right) / \mathrm{i}=1-\mathrm{P}_{\mathrm{r}}\left(\mathrm{t}_{0}\right)=1-\mathrm{F}\left(\mathrm{t}_{0}\right)=1-\frac{\mathrm{t}_{0}}{\mathrm{t}_{\mathrm{N}}} \quad$ if $\quad 0 \leq \mathrm{t}_{0} \leq \mathrm{t}_{\mathrm{N}}=1000$ 
Abdo Abou Jaoude / Journal of Mathematics and Statistics 10 (1): 1-24, 2014

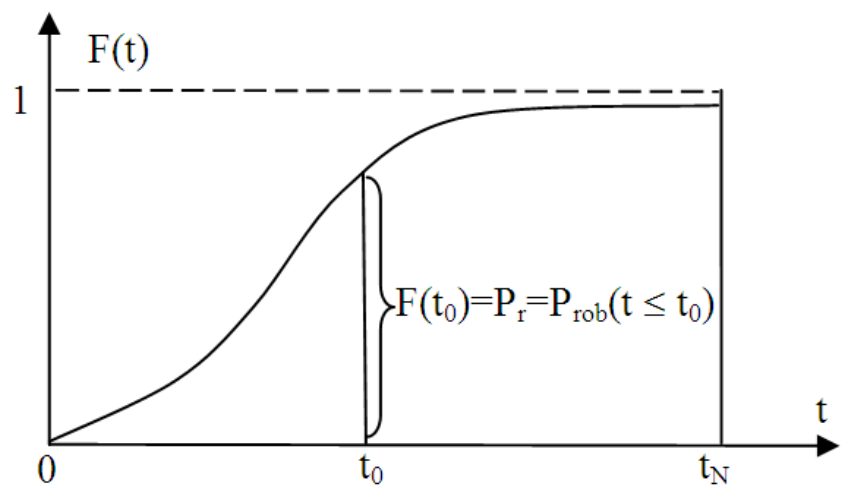

Fig. 3. Occurrence probability

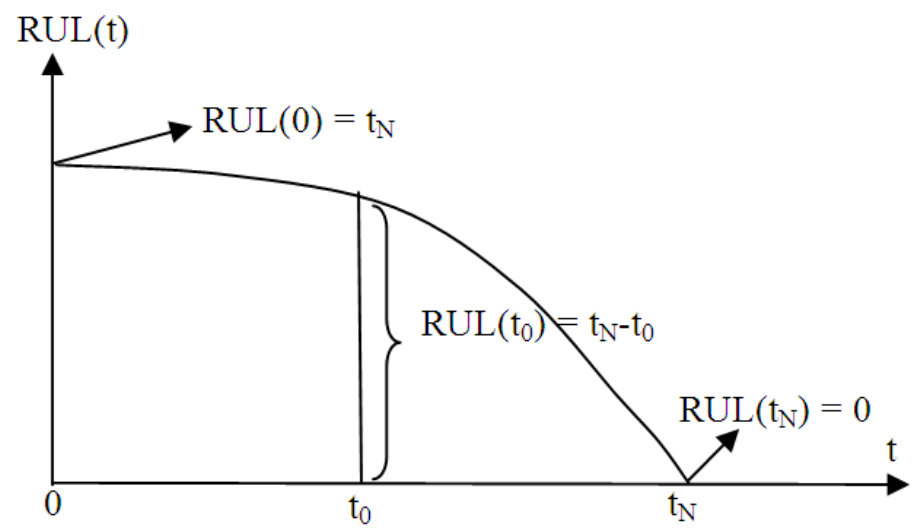

Fig. 4. RUL prognostic model

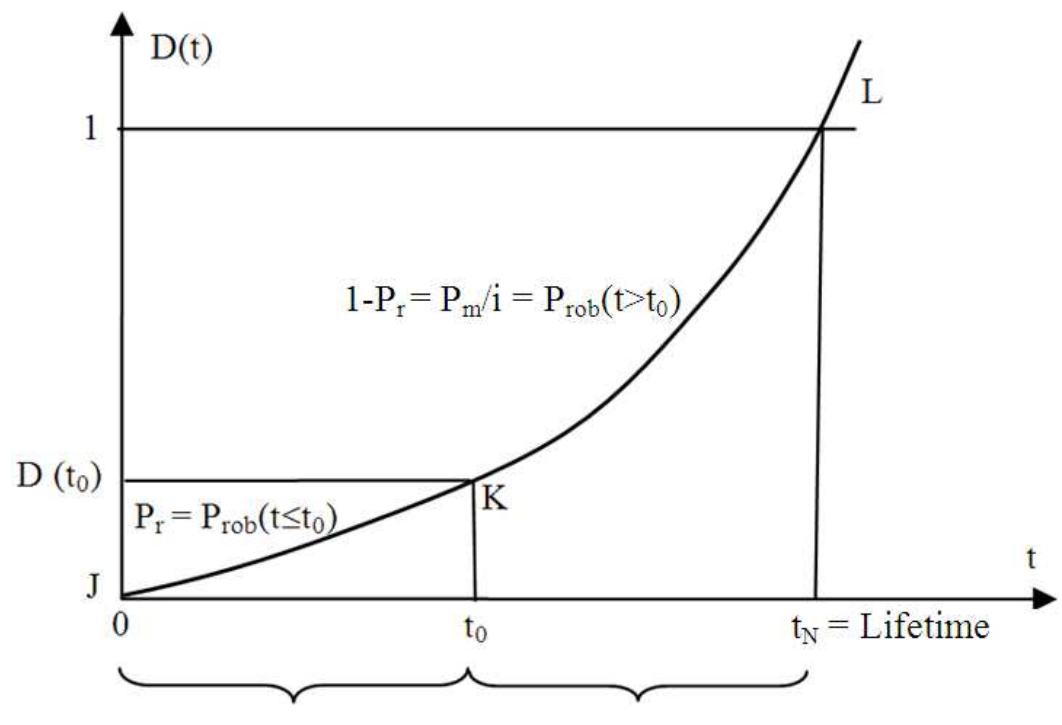

Fig. 5. Degradation prognostic model 
We note that $\mathrm{P}_{\mathrm{m}}\left(\mathrm{t}_{0}\right) / \mathrm{i}$ is a non-increasing function.

\subsubsection{The Degree of Our Knowledge DOK}

DOK is the measure of our certain knowledge (100\% probability) about the expected event, it does not include any uncertain knowledge (with probability less than $100 \%$ ):

$$
\begin{aligned}
\operatorname{DOK}\left(\mathrm{t}_{0}\right) & =\mathrm{Pc}^{2}\left(\mathrm{t}_{0}\right)+2 \mathrm{P}_{\mathrm{r}}\left(\mathrm{t}_{0}\right) \mathrm{P}_{\mathrm{m}}\left(\mathrm{t}_{0}\right) \\
= & 1-2 \cdot \mathrm{P}_{\mathrm{rob}}(\mathrm{E}) \cdot \mathrm{P}_{\mathrm{rob}}(\overline{\mathrm{E}})=1-2 \cdot \mathrm{P}_{\mathrm{r}}\left(\mathrm{t}_{0}\right) \cdot\left[1-\mathrm{P}_{\mathrm{r}}\left(\mathrm{t}_{0}\right)\right] \\
= & 1-2 \cdot \mathrm{F}\left(\mathrm{t}_{0}\right) \cdot\left[1-\mathrm{F}\left(\mathrm{t}_{0}\right)\right]=1-2 \cdot \frac{\mathrm{t}_{0}}{\mathrm{t}_{\mathrm{N}}} \cdot\left(1-\frac{\mathrm{t}_{0}}{\mathrm{t}_{\mathrm{N}}}\right) \\
= & 1-2 \cdot \frac{\mathrm{t}_{0}}{\mathrm{t}_{\mathrm{N}}}+2 \cdot\left(\frac{\mathrm{t}_{0}}{\mathrm{t}_{\mathrm{N}}}\right)^{2}
\end{aligned}
$$

Which is a parabola concave upward having a vertex (a minimum) at:

$$
\left(\mathrm{t}_{0}=\frac{\mathrm{t}_{\mathrm{N}}}{2}=500=0.5 \times 10^{3}, 0.5\right)
$$

\subsubsection{The Chaotic Factor Chf and MChf:}

$$
\begin{aligned}
\operatorname{Chf}\left(\mathrm{t}_{0}\right) & =2 i \mathrm{P}_{\mathrm{r}}\left(\mathrm{t}_{0}\right) \mathrm{P}_{\mathrm{m}}\left(\mathrm{t}_{0}\right)=-2 \cdot \mathrm{P}_{\mathrm{rob}}(\mathrm{E}) \cdot \mathrm{P}_{\mathrm{rob}}(\overline{\mathrm{E}}) \\
& =-2 \cdot \mathrm{P}_{\mathrm{r}}\left(\mathrm{t}_{0}\right) \cdot\left[1-\mathrm{P}_{\mathrm{r}}\left(\mathrm{t}_{0}\right)\right]=-2 \cdot \mathrm{F}\left(\mathrm{t}_{0}\right) \cdot\left[1-\mathrm{F}\left(\mathrm{t}_{0}\right)\right] \\
& =-2 \cdot \frac{\mathrm{t}_{0}}{\mathrm{t}_{\mathrm{N}}} \cdot\left(1-\frac{\mathrm{t}_{0}}{\mathrm{t}_{\mathrm{N}}}\right)=-2 \cdot \frac{\mathrm{t}_{0}}{\mathrm{t}_{\mathrm{N}}}+2 \cdot\left(\frac{\mathrm{t}_{0}}{\mathrm{t}_{\mathrm{N}}}\right)^{2}
\end{aligned}
$$

Which is a parabola concave upward having a vertex (a minimum) at:

$$
\left(\mathrm{t}_{0}=\frac{\mathrm{t}_{\mathrm{N}}}{2}=500=0.5 \times 10^{3},-0.5\right)
$$

Therefore, we can infer the magnitude of the chaotic factor MChf:

$$
\begin{aligned}
& \operatorname{MChf}\left(t_{0}\right)=\left|\operatorname{Chf}\left(t_{0}\right)\right|=\left|-2 \cdot P_{r}\left(t_{0}\right) \cdot\left[1-P_{r}\left(t_{0}\right)\right]\right| \\
& =2 \cdot P_{r}\left(t_{0}\right) \cdot\left[1-P_{r}\left(t_{0}\right)\right]=2 \cdot F\left(t_{0}\right) \cdot\left[1-F\left(t_{0}\right)\right] \\
& =2 \cdot \frac{t_{0}}{t_{N}} \cdot\left(1-\frac{t_{0}}{t_{N}}\right)=2 \cdot \frac{t_{0}}{t_{N}}-2 \cdot\left(\frac{t_{0}}{t_{N}}\right)^{2}
\end{aligned}
$$

Which is a parabola concave downward having a vertex (a maximum) at:

$$
\left(\mathrm{t}_{0}=\frac{\mathrm{t}_{\mathrm{N}}}{2}=500=0.5 \times 10^{3}, 0.5\right)
$$

\subsubsection{Pc: The Probability in the Complex Set C:}

$$
\begin{aligned}
& \operatorname{Pc}^{2}\left(t_{0}\right)=\operatorname{DOK}\left(t_{0}\right)-\operatorname{Chf}\left(t_{0}\right) \\
& =1-2 \cdot \frac{\mathrm{t}_{0}}{t_{\mathrm{N}}}+2 \cdot\left(\frac{\mathrm{t}_{0}}{\mathrm{t}_{\mathrm{N}}}\right)^{2}+2 \cdot \frac{\mathrm{t}_{0}}{\mathrm{t}_{\mathrm{N}}}-2 \cdot\left(\frac{\mathrm{t}_{0}}{\mathrm{t}_{\mathrm{N}}}\right)^{2}=1 \Rightarrow \operatorname{Pc}\left(\mathrm{t}_{0}\right)=1
\end{aligned}
$$

Thus we deduce that in the set $\mathrm{C}$, we have a complete knowledge of the random variable since $\mathrm{Pc}=1$.

\subsubsection{The Intersection Point:}

$$
\begin{aligned}
& \mathrm{P}_{\mathrm{r}}\left(\mathrm{t}_{0}\right)=\mathrm{P}_{\mathrm{m}}\left(\mathrm{t}_{0}\right) / \mathrm{i} \Leftrightarrow \frac{\mathrm{t}_{0}}{\mathrm{t}_{\mathrm{N}}}=1-\frac{\mathrm{t}_{0}}{\mathrm{t}_{\mathrm{N}}} \Leftrightarrow 2 \cdot \frac{\mathrm{t}_{0}}{\mathrm{t}_{\mathrm{N}}} \\
& =1 \Leftrightarrow \mathrm{t}_{0}=\frac{\mathrm{t}_{\mathrm{N}}}{2}=\frac{1000}{2}=500 \\
& \text { and } \mathrm{P}_{\mathrm{r}}\left(\mathrm{t}_{0}=500\right)=\frac{500}{1000}=0.5 \text { and } \\
& \mathrm{P}_{\mathrm{m}}\left(\mathrm{t}_{0}=500\right) / \mathrm{i}=1-\frac{500}{1000}=1-0.5=0.5
\end{aligned}
$$

So $\mathrm{P}_{\mathrm{r}}\left(\mathrm{t}_{0}\right)$ and $\mathrm{P}_{\mathrm{m}}\left(\mathrm{t}_{0}\right) / \mathrm{i}$ intersect at $(500,0.5)$.

Moreover, the minimum of DOK and the maximum of MChf occur at $(500,0.5)$.

So we conclude that $\mathrm{P}_{\mathrm{r}}\left(\mathrm{t}_{0}\right), \mathrm{P}_{\mathrm{m}}\left(\mathrm{t}_{0}\right) / \mathrm{i}$, DOK and MChf all intersect at (500, 0.5) (Fig. 6-9).

\subsubsection{The EKA Parameters Analysis in the Prognostic of Degradation:}

We note from the figure below that the DOK is maximum $(\mathrm{DOK}=1)$ when $\mathrm{MChf}$ is minimum $(\mathrm{MChf}=$ 0 ) (points $\mathrm{J} \& \mathrm{~L}$ ) and that means when the magnitude of the chaotic factor (MChf) decreases our certain knowledge increases.

At the beginning $P_{r}\left(t_{0}\right)=t_{0} / t_{N}=0 / t_{N}=0$, the system is intact (zero damage: $\mathrm{D}=0$ ) and has zero chaotic factor before any usage, at this instant $\operatorname{DOK}(0)=1$ and $\operatorname{RUL}(0)$ $=\mathrm{t}_{\mathrm{N}}-0=\mathrm{t}_{\mathrm{N}}$ with $\operatorname{Pc}(0)=1$. Afterward, $0<\mathrm{t}_{0}<\mathrm{t}_{\mathrm{N}}, \operatorname{RUL}\left(\mathrm{t}_{0}\right)=$ $\mathrm{t}_{\mathrm{N}}-\mathrm{t}_{0}$ with $\mathrm{P}_{\mathrm{r}}\left(\mathrm{t}_{0}\right)=\mathrm{t}_{0} / \mathrm{t}_{\mathrm{N}} \neq 0$ and $\operatorname{Pc}\left(\mathrm{t}_{0}\right)=1$ and MChf starts to increase during the functioning due to the environment and intrinsic conditions thus leading to a decrease in DOK until they both reach 0.5 at $\mathrm{t}_{0}=\mathrm{t}_{\mathrm{N}} / 2=500$ (point K) where $\operatorname{RUL}\left(\mathrm{t}_{\mathrm{N}} / 2\right)=\mathrm{t}_{\mathrm{N}} / 2=500$. Since the real probability $\mathrm{P}_{\mathrm{r}}$ is a uniform distribution MChf will intersect with DOK at the point $\left(\mathrm{t}_{\mathrm{N}} / 2=500,0.5\right)$ (point $\mathrm{K}$ ).

With the increase of the time of functioning, MChf returns to zero and the DOK returns to 1 where we reach total damage $(D=1)$ and hence the total failure of the system (point L). At this last point the failure here is certain, $\mathrm{P}_{\mathrm{r}}\left(\mathrm{t}_{\mathrm{N}}\right)=\mathrm{t}_{\mathrm{N}} / \mathrm{t}_{\mathrm{N}}=1$ and $\operatorname{RUL}\left(\mathrm{t}_{\mathrm{N}}\right)=\mathrm{t}_{\mathrm{N}}-\mathrm{t}_{\mathrm{N}}=$ 0 with $\operatorname{Pc}\left(t_{N}\right)=1$, so the logical explanation of the value $\mathrm{DOK}=1$ follows (Fig. 10). 
Abdo Abou Jaoude / Journal of Mathematics and Statistics 10 (1): 1-24, 2014

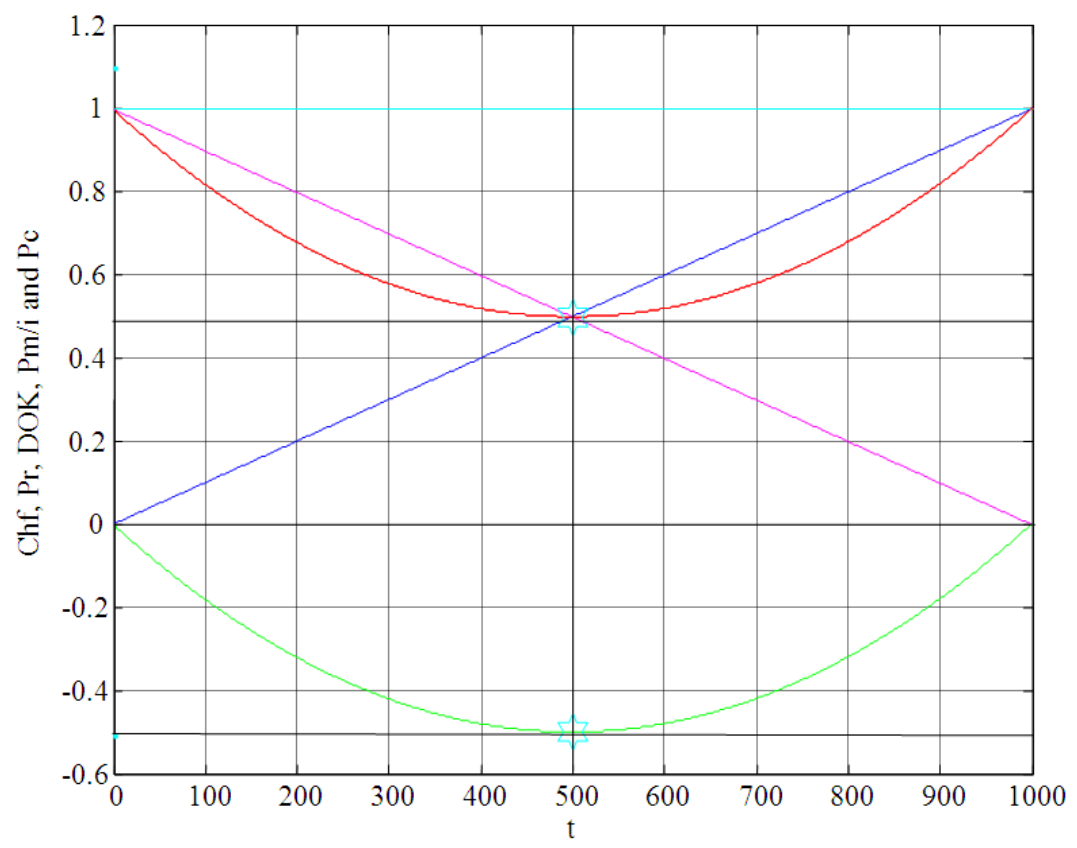

---- Chf: Chaotic factor

---- Pr: Real probability

---- DOK: Degree of our knowledge

--- Pm/i: Complementary probability

-.-- Pc: Probability in the set C

Fig. 6. EKA parameters in uniform probability distribution

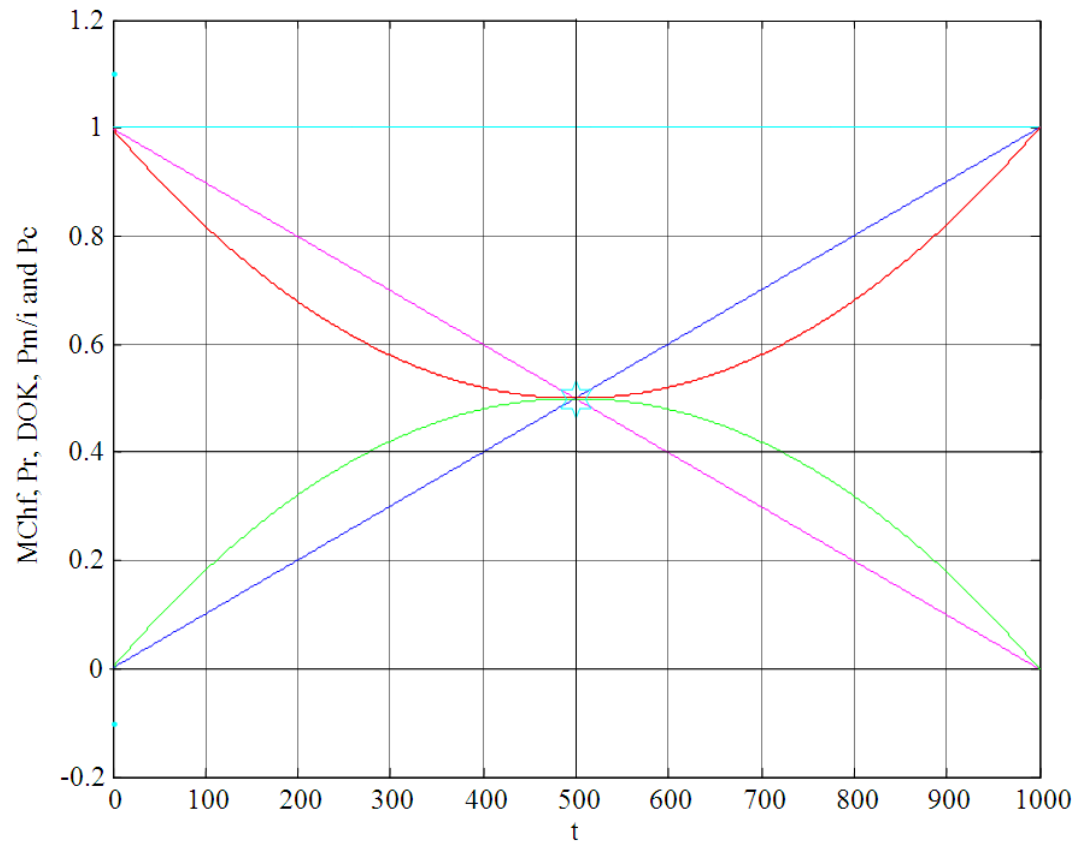

Fig. 7. EKA parameters in uniform probability distribution 
Abdo Abou Jaoude / Journal of Mathematics and Statistics 10 (1): 1-24, 2014

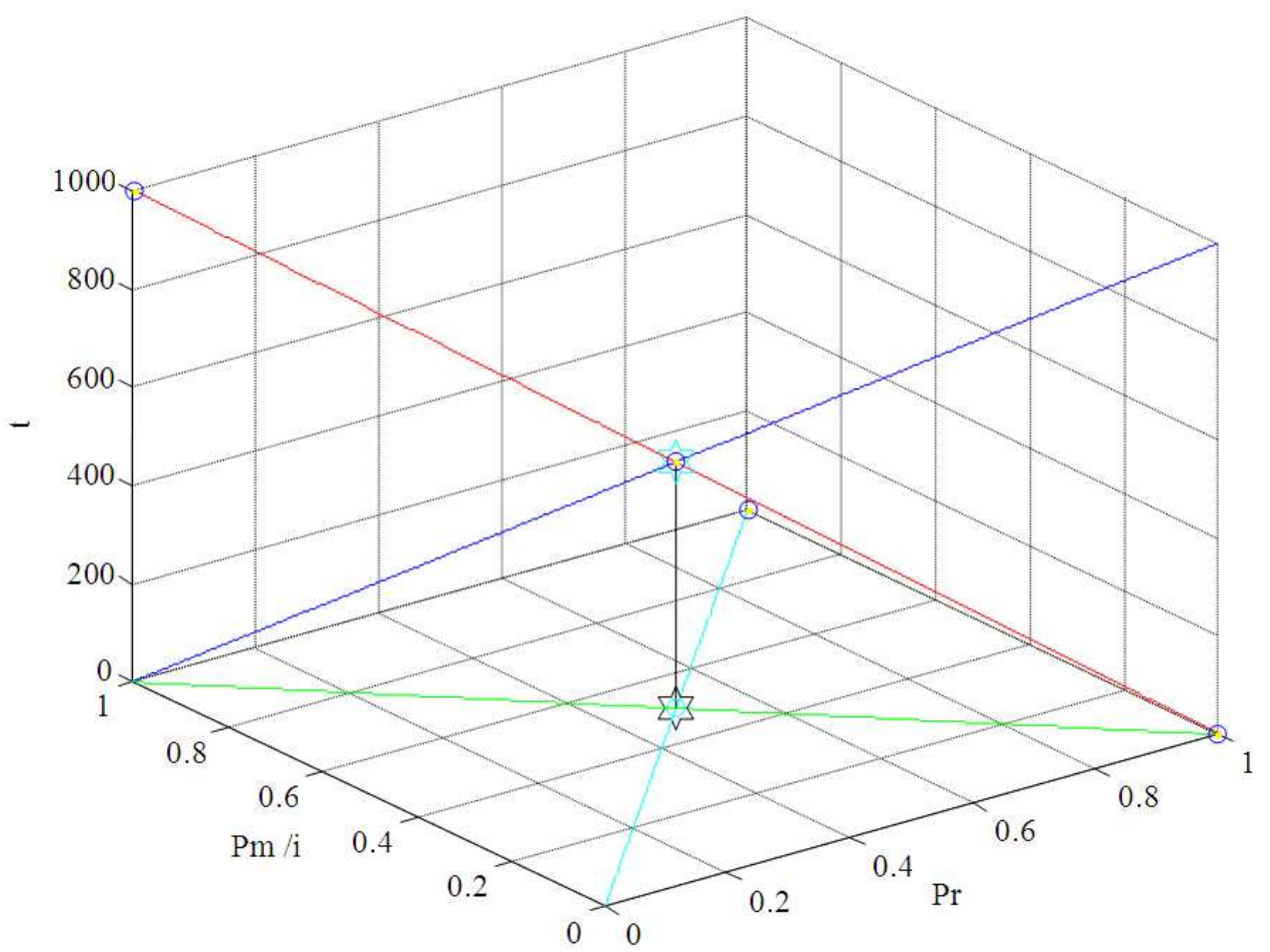

Fig. 8. The probabilities $\operatorname{Pr}$ and $\mathrm{Pm} / \mathrm{i}$ in terms of $\mathrm{t}$ and of each other

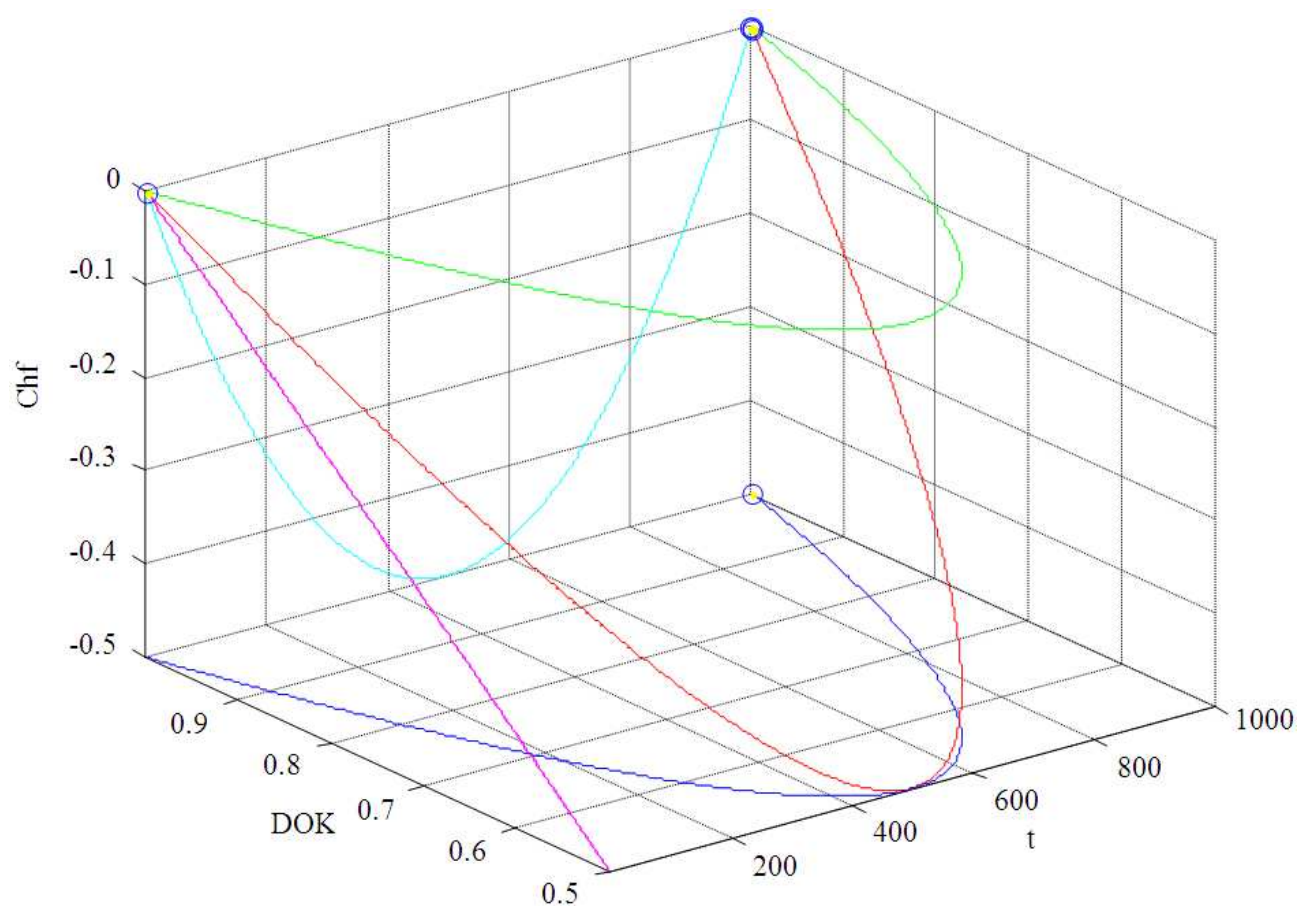

Fig. 9. DOK and $\mathrm{Chf}$ in terms of $\mathrm{t}$ and of each other in uniform probability distribution 


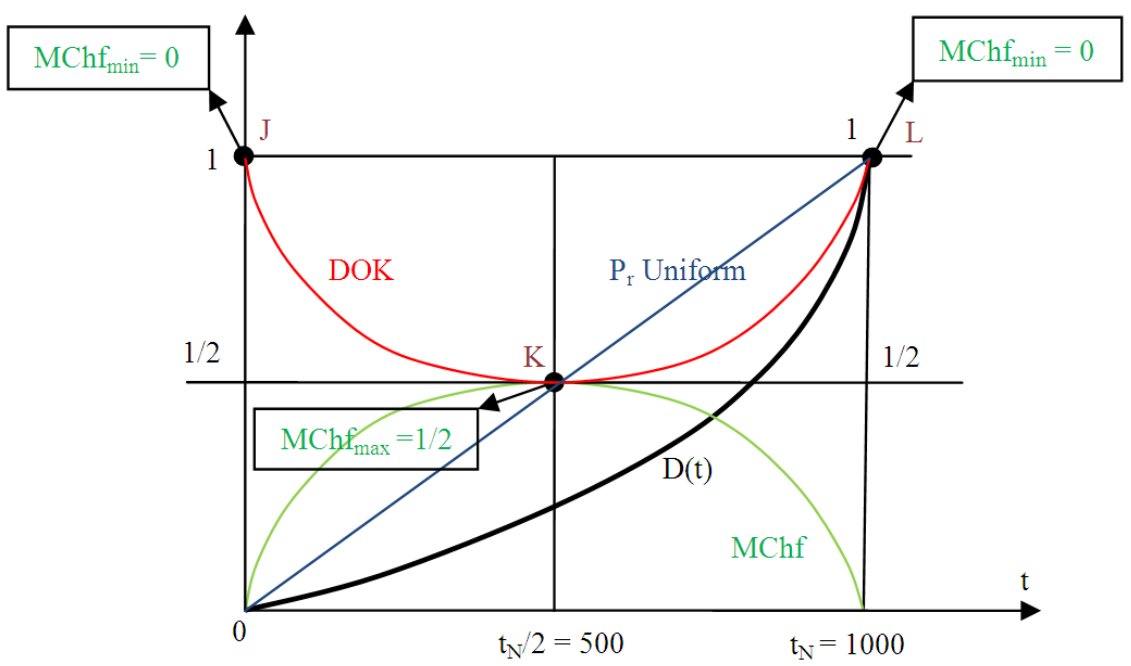

Fig. 10. EKA parameters and the prognostic of degradation

We note that the same logic and analysis apply concerning the degradation and the remaining useful lifetime for the all the six probability distributions.

\subsection{The Logarithmic Distribution:}

With a probability density function:

$$
\begin{aligned}
& f(t)=\frac{d F(t)}{d t}=\left\{\begin{array}{cc}
\frac{\alpha}{1+\alpha t} & \text { if } \quad 0 \leq t \leq t_{N} \\
0 & \text { elsewhere }
\end{array}\right. \\
& \text { where } \alpha=(e-1) / 1000=0.001718281 \ldots
\end{aligned}
$$

and a cumulative distribution function:

$$
F\left(t_{0}\right)=\int_{-\infty}^{t_{0}} f(t) d t=\int_{0}^{t_{0}} f(t) d t=\left\{\begin{array}{ccc}
\operatorname{Ln}\left(1+\alpha t_{0}\right) & \text { if } & 0 \leq t_{0} \leq t_{N} \\
0 & \text { elsewhere }
\end{array}\right.
$$

We have taken the domain for the logarithmic variable $\mathrm{t}_{0}=\left[0, \mathrm{t}_{\mathrm{N}}=1000\right]$ where $\mathrm{dt}_{0}=0.1$.

\subsubsection{The Real Probability $P_{\mathrm{r}}$ :}

$$
\mathrm{P}_{\mathrm{r}}=\mathrm{F}\left(\mathrm{t}_{0}\right)=\operatorname{Ln}\left(1+\alpha \mathrm{t}_{0}\right) \quad \text { if } \quad 0 \leq \mathrm{t}_{0} \leq \mathrm{t}_{\mathrm{N}}=1000
$$

We note that $\mathrm{P}_{\mathrm{r}}$ is a non-decreasing function.

\subsubsection{The Complementary Probability $P_{m} /$ i:}

$$
\begin{aligned}
& \mathrm{P}_{\mathrm{m}} / \mathrm{i}=1-\mathrm{P}_{\mathrm{r}}=1-\mathrm{F}\left(\mathrm{t}_{0}\right)=1-\operatorname{Ln}\left(1+\alpha \mathrm{t}_{0}\right) \\
& \text { if } 0 \leq \mathrm{t}_{0} \leq \mathrm{t}_{\mathrm{N}}=1000
\end{aligned}
$$

We note that $\mathrm{P}_{\mathrm{m}} / \mathrm{i}$ is a non-increasing function.

\subsubsection{The Degree of Our Knowledge DOK:}

DOK is the measure of our certain knowledge (100\% probability) about the expected event, it does not include any uncertain knowledge (with probability less than $100 \%$ ):

$$
\begin{aligned}
& \text { DOK }=1-2 \cdot P_{\mathrm{r}} \cdot\left(1-\mathrm{P}_{\mathrm{r}}\right)=1-2 \cdot \mathrm{P}_{\mathrm{rob}}(\mathrm{E}) \cdot \mathrm{P}_{\mathrm{rob}}(\overline{\mathrm{E}}) \\
& =1-2 \cdot \mathrm{F}\left(\mathrm{t}_{0}\right) \cdot\left[1-\mathrm{F}\left(\mathrm{t}_{0}\right)\right] \\
& =1-2 \cdot \operatorname{Ln}\left(1+\alpha \mathrm{t}_{0}\right) \cdot\left[1-\operatorname{Ln}\left(1+\alpha \mathrm{t}_{0}\right)\right] \\
& =1-2 \cdot \operatorname{Ln}\left(1+\alpha \mathrm{t}_{0}\right)+2\left[\operatorname{Ln}\left(1+\alpha \mathrm{t}_{0}\right)\right]^{2}
\end{aligned}
$$

which is a curve concave upward having a minimum at:

$$
\left(\mathrm{t}_{0}=377.54,0.5\right)
$$

\subsubsection{The Chaotic Factor Chf and MChf:}

$$
\begin{aligned}
& \text { Chf }=-2 \cdot P_{r} \cdot\left(1-P_{r}\right)=-2 \cdot P_{\text {rob }}(E) \cdot P_{\text {rob }}(\bar{E}) \\
& =-2 \cdot F\left(t_{0}\right) \cdot\left[1-F\left(t_{0}\right)\right] \\
& =-2 \cdot \operatorname{Ln}\left(1+\alpha t_{0}\right) \cdot\left[1-\operatorname{Ln}\left(1+\alpha t_{0}\right)\right] \\
& =-2 \cdot \operatorname{Ln}\left(1+\alpha t_{0}\right)+2 \cdot\left[\operatorname{Ln}\left(1+\alpha t_{0}\right)\right]^{2}
\end{aligned}
$$

which is a curve concave upward having a minimum at:

$$
\left(t_{0}=377.54,-0.5\right)
$$


Therefore, we can infer the magnitude of the chaotic factor MChf:

$$
\begin{aligned}
& \operatorname{MChf}\left(\mathrm{t}_{0}\right)=\left|\operatorname{Chf}\left(\mathrm{t}_{0}\right)\right|=\left|-2 \cdot \mathrm{P}_{\mathrm{r}}\left(\mathrm{t}_{0}\right) \cdot\left[1-\mathrm{P}_{\mathrm{r}}\left(\mathrm{t}_{0}\right)\right]\right| \\
& =2 \cdot \mathrm{P}_{\mathrm{r}}\left(\mathrm{t}_{0}\right) \cdot\left[1-\mathrm{P}_{\mathrm{r}}\left(\mathrm{t}_{0}\right)\right]=2 \cdot \mathrm{F}\left(\mathrm{t}_{0}\right) \cdot\left[1-\mathrm{F}\left(\mathrm{t}_{0}\right)\right] \\
& =2 \cdot \operatorname{Ln}\left(1+\alpha \mathrm{t}_{0}\right) \cdot\left[1-\operatorname{Ln}\left(1+\alpha \mathrm{t}_{0}\right)\right] \\
& =2 \cdot \operatorname{Ln}\left(1+\alpha \mathrm{t}_{0}\right)-2 \cdot\left[\operatorname{Ln}\left(1+\alpha \mathrm{t}_{0}\right)\right]^{2}
\end{aligned}
$$

Which is a curve concave downward having a maximum at:

$$
\left(\mathrm{t}_{0}=377.54,0.5\right)
$$

\subsubsection{Pc: The Probability in the Complex Set C:}

$$
\begin{aligned}
& \mathrm{Pc}^{2}=\mathrm{DOK}-\mathrm{Chf}=1-2 \cdot \ln \left(1+\alpha \mathrm{t}_{0}\right)+2 \cdot\left[\ln \left(1+\alpha \mathrm{t}_{0}\right)\right]^{2} \\
& +2 \cdot \ln \left(1+\alpha \mathrm{t}_{0}\right)-2 \cdot\left[\ln \left(1+\alpha \mathrm{t}_{0}\right)\right]^{2}=1 \Rightarrow \mathrm{Pc}=1
\end{aligned}
$$

Thus we deduce that in the set $\mathrm{C}$, we have a complete knowledge of the random variable since $\mathrm{Pc}=1$.

\subsubsection{The Intersection Point:}

$$
\begin{aligned}
& \mathrm{P}_{\mathrm{r}}\left(\mathrm{t}_{0}\right)=\mathrm{P}_{\mathrm{m}}\left(\mathrm{t}_{0}\right) / \mathrm{i} \Leftrightarrow \operatorname{Ln}\left(1+\alpha \mathrm{t}_{0}\right)=1-\operatorname{Ln}\left(1+\alpha \mathrm{t}_{0}\right) \\
& \Leftrightarrow 2 \cdot \operatorname{Ln}\left(1+\alpha \mathrm{t}_{0}\right)=1 \Leftrightarrow \operatorname{Ln}\left(1+\alpha \mathrm{t}_{0}\right)=\frac{1}{2} \\
& \Leftrightarrow \mathrm{t}_{0}=(\exp (0.5)-1) / \alpha=377.54 \\
& \text { and } \mathrm{P}_{\mathrm{r}}\left(\mathrm{t}_{0}=377.54\right)=\operatorname{Ln}(1+\alpha \times 377.54)=0.5 \\
& \text { and } \mathrm{P}_{\mathrm{m}}\left(\mathrm{t}_{0}=377.54\right) / \mathrm{i}=1-\operatorname{Ln}(1+\alpha \times 377.54) \\
& =1-0.5=0.5
\end{aligned}
$$

So $\mathrm{P}_{\mathrm{r}}\left(\mathrm{t}_{0}\right)$ and $\mathrm{P}_{\mathrm{m}}\left(\mathrm{t}_{0}\right) / \mathrm{i}$ intersect at $(377.54,0.5)$.

Moreover, the minimum of DOK and the maximum of MChf occur at $(377.54,0.5)$.

So we conclude that $\mathrm{P}_{\mathrm{r}}\left(\mathrm{t}_{0}\right), \mathrm{P}_{\mathrm{m}}\left(\mathrm{t}_{0}\right) / \mathrm{i}$, DOK and MChf all intersect at $(377.54,0.5)$ (Fig. 11-13).

\subsubsection{The EKA Parameters Analysis in the Prognostic of Degradation:}

In this case, we note from the figure below that the DOK is maximum ( $\mathrm{DOK}=1)$ when $\mathrm{MChf}$ is minimum (MChf = 0) (points J \& L). Afterward, MChf starts to increase with the decrease of DOK until it reaches 0.5 at $\mathrm{t}_{0}=377.54$ (point $\mathrm{K}$ ). Since the real probability $\mathrm{P}_{\mathrm{r}}$ is a logarithmic distribution (convex curve) it will intersect with DOK at the point $(377.54,0.5)$ (point K). With the increase of $t_{0}$, MChf returns to zero and the DOK returns to 1 where we reach total damage $(D=1)$ and hence the total certain failure $\left(\mathrm{P}_{\mathrm{r}}=1\right)$ of the system (point $\mathrm{L}$ ). We note that the point $\mathrm{K}$ is no more at the middle of DOK since the distribution is not anymore uniform and symmetric.

At each instant $t_{0}$, the remaining useful lifetime $\operatorname{RUL}\left(\mathrm{t}_{0}\right)$ is certainly predicted in the complex set $\mathrm{C}$ with $\mathrm{Pc}$ maintained as equal to one through a continuous compensation between DOK and Chf. This compensation is from instant $\mathrm{t}_{0}=0$ where $\mathrm{D}\left(\mathrm{t}_{0}\right)=0$ until the failure instant $t_{N}$ where $D\left(t_{N}\right)=1$ (Fig. 11).

\subsection{The Power Probability Distribution:}

With a probability density function:

$$
f(t)=\frac{d F(t)}{d t}=\left\{\begin{array}{cc}
\frac{14 . t^{13}}{1000^{14}} & \text { if } \quad 0 \leq t \leq t_{N} \\
0 & \text { elsewhere }
\end{array}\right.
$$

and a cumulative distribution function:

$$
F\left(t_{0}\right)=\int_{-\infty}^{t_{0}} f(t) d t=\int_{0}^{t_{0}} f(t) d t=\left\{\begin{array}{ccc}
\frac{t_{0}^{14}}{1000^{14}} & \text { if } & 0 \leq t_{0} \leq t_{N} \\
0 & \text { elsewhere }
\end{array}\right.
$$

We have taken the domain for the power variable $t_{0}=$ $\left[0, \mathrm{t}_{\mathrm{N}}=1000\right]$ and $\mathrm{dt}_{0}=0.1$.

\subsubsection{The Real Probability $P_{r}$ :}

$$
\mathrm{P}_{\mathrm{r}}=\mathrm{F}\left(\mathrm{t}_{0}\right)=\frac{\mathrm{t}_{0}^{14}}{1000^{14}} \quad \text { if } \quad 0 \leq \mathrm{t}_{0} \leq \mathrm{t}_{\mathrm{N}}=1000
$$

We note that $\mathrm{P}_{\mathrm{r}}$ is a non-decreasing function.

\subsubsection{The Complementary Probability $P_{m} / \mathbf{i}$ :}

$$
\begin{aligned}
& \mathrm{P}_{\mathrm{m}} / \mathrm{i}=1-\mathrm{P}_{\mathrm{r}}=1-\mathrm{F}\left(\mathrm{t}_{0}\right)=1-\frac{\mathrm{t}_{0}^{14}}{1000^{14}} \\
& \text { if } \quad 0 \leq \mathrm{t}_{0} \leq \mathrm{t}_{\mathrm{N}}=1000
\end{aligned}
$$

We note that $\mathrm{P}_{\mathrm{m}} / \mathrm{i}$ is a non-increasing function. 
Abdo Abou Jaoude / Journal of Mathematics and Statistics 10 (1): 1-24, 2014

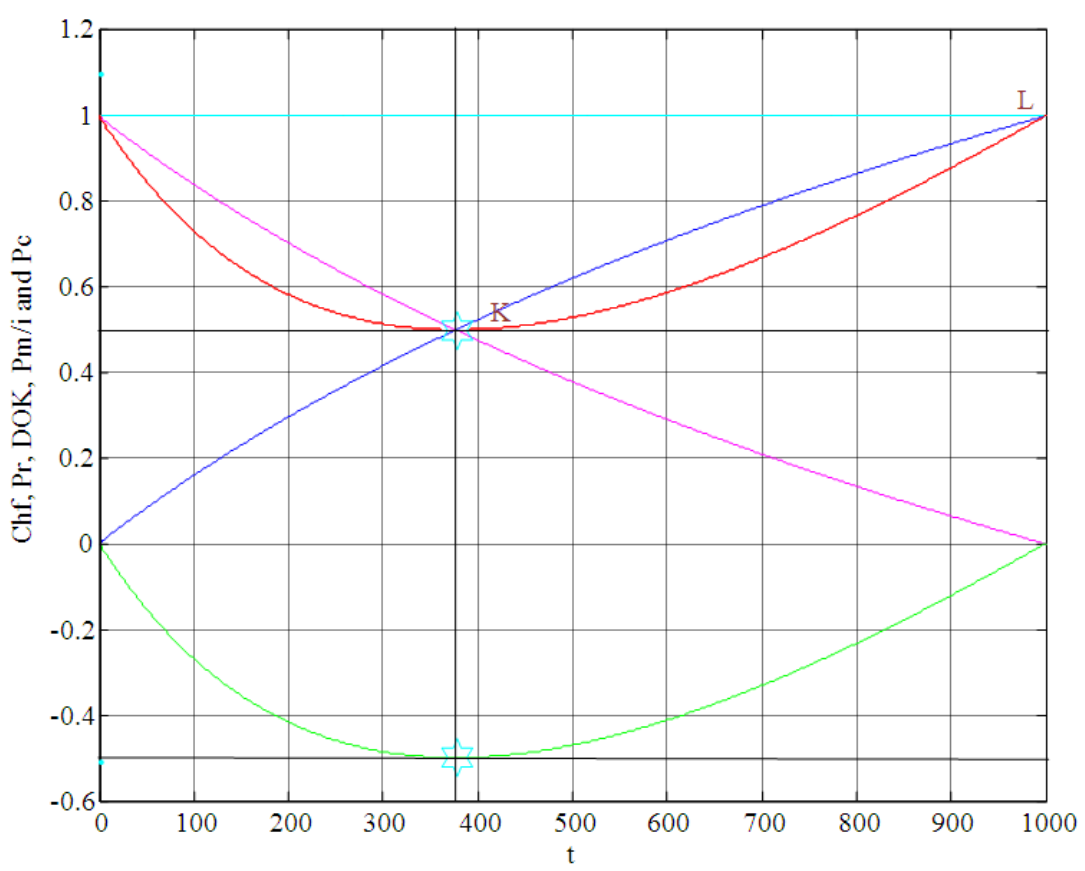

---- Chf: Chaotic factor

---- Pr: Real probability

---- DOK: Degree of our knowledge

--- Pm/i: Complementary probability

---- Pc: Probability in the set C

Fig. 11. EKA parameters in logarithmic cumulative distribution

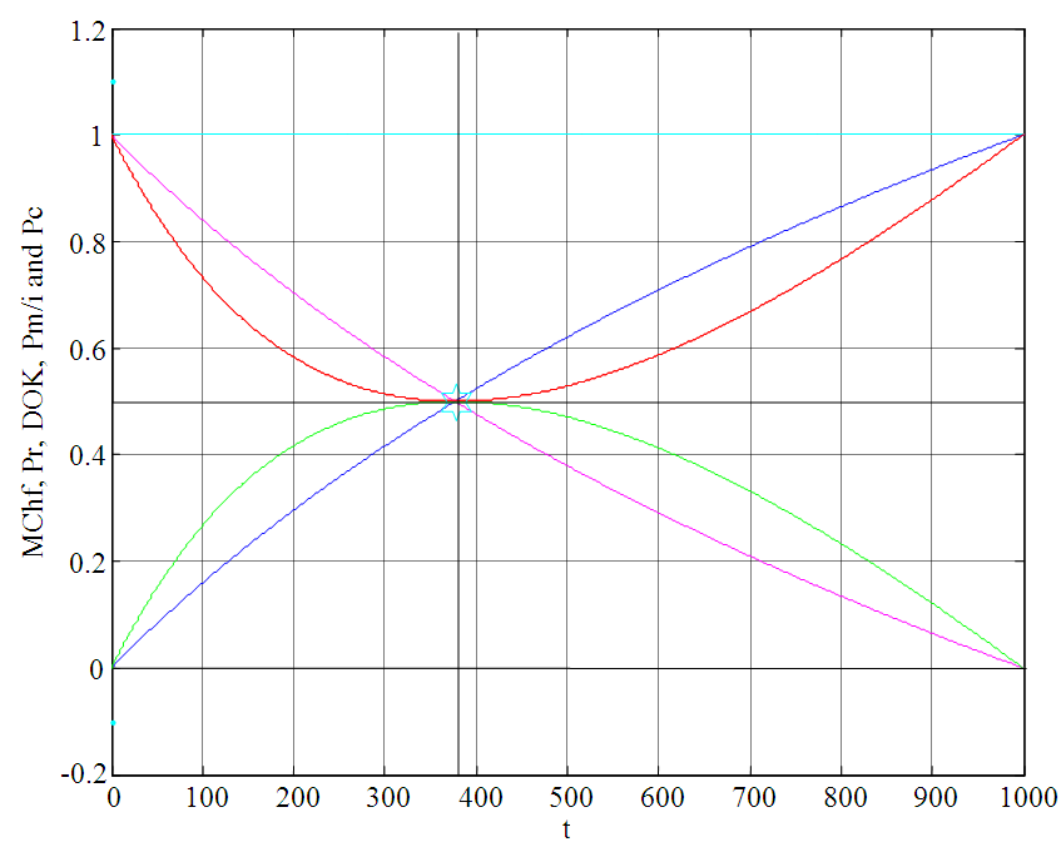

Fig. 12. EKA parameters in logarithmic cumulative distribution 


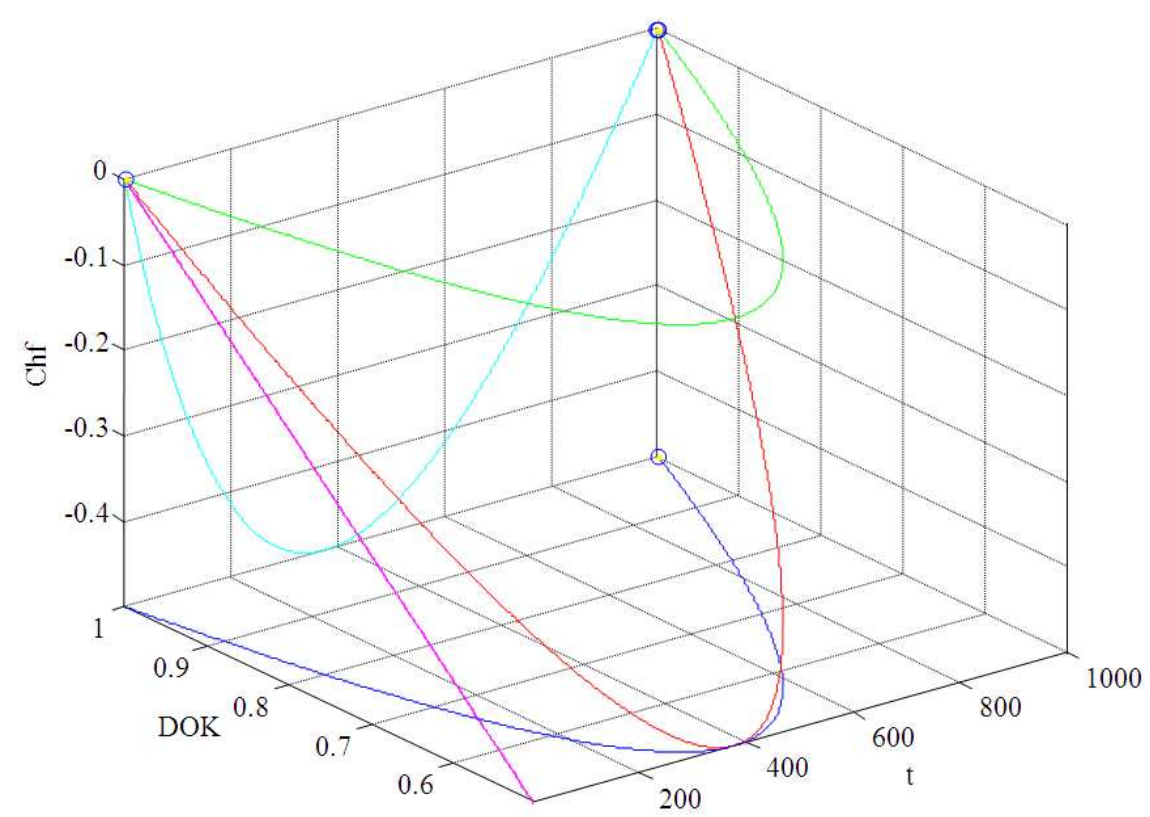

Fig. 13. DOK and Chf in terms of $t$ and of each other in logarithmic cumulative distribution

\subsubsection{The Degree of Our Knowledge DOK:}

DOK is the measure of our certain knowledge (100\% probability) about the expected event, it does not include any uncertain knowledge (with probability less than $100 \%$ ):

$$
\begin{aligned}
& \text { DOK }=1-2 \cdot P_{\mathrm{r}} \cdot\left(1-\mathrm{P}_{\mathrm{r}}\right)=1-2 \cdot \mathrm{P}_{\mathrm{rob}}(\mathrm{E}) \cdot \mathrm{P}_{\mathrm{rob}}(\overline{\mathrm{E}}) \\
& =1-2 \cdot \mathrm{F}\left(\mathrm{t}_{\mathrm{t}}\right) \cdot\left[1-\mathrm{F}\left(\mathrm{t}_{0}\right)\right] \\
& =1-2 \cdot \frac{\mathrm{t}_{0}^{14}}{1000^{14}} \cdot\left(1-\frac{\mathrm{t}_{0}^{14}}{1000^{14}}\right)=1-2 \cdot \frac{\mathrm{t}_{0}^{14}}{1000^{14}} \\
& +2 \cdot\left(\frac{\mathrm{t}_{0}^{14}}{1000^{14}}\right)^{2}=1-2 \cdot \frac{\mathrm{t}_{0}^{14}}{1000^{14}}+2 \cdot \frac{\mathrm{t}_{0}^{28}}{1000^{28}}
\end{aligned}
$$

Which is a curve concave upward having a minimum at:

$$
\left(\mathrm{t}_{0}=951.7,0.5\right)
$$

\subsubsection{The Chaotic Factor Chf and MChf:}

$$
\begin{aligned}
& \mathrm{Chf}=-2 \cdot \mathrm{P}_{\mathrm{r}} \cdot\left(1-\mathrm{P}_{\mathrm{r}}\right)=-2 \cdot \mathrm{P}_{\text {rob }}(\mathrm{E}) \cdot \mathrm{P}_{\mathrm{rob}}(\overline{\mathrm{E}}) \\
& =-2 \cdot \mathrm{F}\left(\mathrm{t}_{0}\right) \cdot\left[1-\mathrm{F}\left(\mathrm{t}_{0}\right)\right] \\
& =-2 \cdot \frac{\mathrm{t}_{0}^{14}}{1000^{14}} \cdot\left(1-\frac{\mathrm{t}_{0}^{14}}{1000^{14}}\right)=-2 \cdot \frac{\mathrm{t}_{0}^{14}}{1000^{14}}+2 \cdot\left(\frac{\mathrm{t}_{0}^{14}}{1000^{14}}\right)^{2} \\
& =-2 \cdot \frac{\mathrm{t}_{0}^{14}}{1000^{14}}+2 \cdot \frac{\mathrm{t}_{0}^{28}}{1000^{28}}
\end{aligned}
$$

Which is a curve concave upward having a minimum at:

$$
\left(\mathrm{t}_{0}=951.7,-0.5\right)
$$

Therefore, we can infer the magnitude of the chaotic factor MChf:

$$
\begin{aligned}
& \operatorname{MChf}\left(\mathrm{t}_{0}\right)=\left|\operatorname{Chf}\left(\mathrm{t}_{0}\right)\right|=\left|-2 \cdot \mathrm{P}_{\mathrm{r}}\left(\mathrm{t}_{0}\right) \cdot\left[1-\mathrm{P}_{\mathrm{r}}\left(\mathrm{t}_{0}\right)\right]\right| \\
& =2 \cdot \mathrm{P}_{\mathrm{r}}\left(\mathrm{t}_{0}\right) \cdot\left[1-\mathrm{P}_{\mathrm{r}}\left(\mathrm{t}_{0}\right)\right]=2 \cdot \mathrm{F}\left(\mathrm{t}_{0}\right) \cdot\left[1-\mathrm{F}\left(\mathrm{t}_{0}\right)\right] \\
& =2 \cdot \frac{\mathrm{t}_{0}^{14}}{1000^{14}} \cdot\left(1-\frac{\mathrm{t}_{0}^{14}}{1000^{14}}\right)=2 \cdot \frac{\mathrm{t}_{0}^{14}}{1000^{14}}-2 \cdot \frac{\mathrm{t}_{0}^{28}}{1000^{28}}
\end{aligned}
$$

Which is a curve concave downward having a maximum at:

$$
\left(\mathrm{t}_{0}=951.7,0.5\right)
$$

\subsubsection{Pc: The Probability in the Complex Set C:}

$$
\begin{aligned}
& \mathrm{Pc}^{2}=\mathrm{DOK}-\mathrm{Chf}=1-2 \cdot \frac{\mathrm{t}_{0}^{14}}{1000^{14}}+2 \cdot\left(\frac{\mathrm{t}_{0}^{14}}{1000^{14}}\right)^{2} \\
& +2 \cdot \frac{\mathrm{t}_{0}^{14}}{1000^{14}}-2 \cdot\left(\frac{\mathrm{t}_{0}^{14}}{1000^{14}}\right)^{2}=1 \Rightarrow \mathrm{Pc}=1
\end{aligned}
$$

Thus we deduce that in the set $\mathrm{C}$, we have a complete knowledge of the random variable since $\mathrm{Pc}=1$. 


\subsubsection{The Intersection Point:}

$$
\begin{aligned}
& \quad \mathrm{P}_{\mathrm{r}}\left(\mathrm{t}_{0}\right)=\mathrm{P}_{\mathrm{m}}\left(\mathrm{t}_{0}\right) / \mathrm{i} \Leftrightarrow \frac{\mathrm{t}_{0}^{14}}{1000^{14}}=1-\frac{\mathrm{t}_{0}^{14}}{1000^{14}} \\
& \Leftrightarrow 2 \cdot \frac{\mathrm{t}_{0}^{14}}{1000^{14}}=1 \Leftrightarrow \frac{\mathrm{t}_{0}^{14}}{1000^{14}}=\frac{1}{2} \\
& \Leftrightarrow \mathrm{t}_{0}=\sqrt[14]{0.5 \times 1000^{14}}=951.7 \\
& \text { and } \mathrm{P}_{\mathrm{r}}\left(\mathrm{t}_{0}=951.7\right)=\frac{951.7^{14}}{1000^{14}}=0.5 \\
& \text { and } \mathrm{P}_{\mathrm{m}}\left(\mathrm{t}_{0}=951.7\right) / \mathrm{i}=1-\frac{951.7^{14}}{1000^{14}}=1-0.5=0.5
\end{aligned}
$$

So $\mathrm{P}_{\mathrm{r}}\left(\mathrm{t}_{0}\right)$ and $\mathrm{P}_{\mathrm{m}}\left(\mathrm{t}_{0}\right) / \mathrm{i}$ intersect at $(951.7,0.5)$.

Moreover, the minimum of DOK and the maximum of MChf occur at $(951.7,0.5)$.

So we conclude that $\mathrm{P}_{\mathrm{r}}\left(\mathrm{t}_{0}\right), \mathrm{P}_{\mathrm{m}}\left(\mathrm{t}_{0}\right) / \mathrm{i}$, DOK and MChf all intersect at $(951.7,0.5)$ (Fig. 14-16).

\subsubsection{The EKA Parameters Analysis in the Prognostic of Degradation:}

In this case, we note from the figure below that the DOK is maximum $(\mathrm{DOK}=1)$ when MChf is minimum $(\mathrm{MChf}=0)$ (points $\mathrm{J} \& \mathrm{~L})$. Afterward, MChf starts to increase with the decrease of DOK until it reaches 0.5 at $t_{0}=951.7$ (point $K$ ). Since the real probability $P_{r}$ is a power distribution it will intersect with DOK at the point $(951.7,0.5)$ (point $\mathrm{K}$ ). With the increase of $t_{0}$, MChf returns to zero and the DOK returns to 1 where we reach total damage $(\mathrm{D}=1)$ and hence the total certain failure $\left(\mathrm{P}_{\mathrm{r}}=1\right)$ of the system (point $\mathrm{L}$ ). At this last point $L$ the failure here is certain, $P_{r}\left(t_{N}\right)=t_{N} / t_{N}=1$ and $\operatorname{RUL}\left(\mathrm{t}_{\mathrm{N}}\right)=\mathrm{t}_{\mathrm{N}}-\mathrm{t}_{\mathrm{N}}=0$ with $\operatorname{Pc}\left(\mathrm{t}_{\mathrm{N}}\right)=1$, so the logical explanation of the value DOK $=1$ follows. We note that the point $\mathrm{K}$ is no more at the middle of DOK since the distribution is neither uniform nor symmetric (Fig. 14).

\subsection{The Exponential Probability Distribution:}

With a probability density function:

$$
f(t)=\frac{d F(t)}{d t}=\left\{\begin{array}{cc}
\frac{1}{200} \exp \left[-\frac{(1000-t)}{200}\right] & \text { if } 0 \leq t \leq t_{N} \\
0 & \text { elsewhere }
\end{array}\right.
$$

and a cumulative distribution function:

$$
\begin{aligned}
& F\left(t_{0}\right)=\int_{-\infty}^{t_{0}} f(t) d t=\int_{0}^{t_{0}} f(t) d t \\
& =\left\{\begin{array}{cc}
\exp \left[-\frac{\left(1000-\mathrm{t}_{0}\right)}{200}\right] & \text { if } \quad 0 \leq \mathrm{t}_{0} \leq \mathrm{t}_{\mathrm{N}} \\
0 & \text { elsewhere }
\end{array}\right.
\end{aligned}
$$

We have taken the domain for the logarithmic variable $\mathrm{t}_{0}=\left[0, \mathrm{t}_{\mathrm{N}}=1000\right]$ and $\mathrm{dt}_{0}=0.1$.

\subsubsection{The Real Probability $P_{r}$ :}

$$
\begin{aligned}
& \mathrm{P}_{\mathrm{r}}=\mathrm{F}\left(\mathrm{t}_{0}\right)=\exp \left[-\frac{\left(1000-\mathrm{t}_{0}\right)}{200}\right] \\
& \text { if } \quad 0 \leq \mathrm{t}_{0} \leq \mathrm{t}_{\mathrm{N}}=1000
\end{aligned}
$$

We note that $\mathrm{P}_{\mathrm{r}}$ is a non-decreasing function.

\subsubsection{The Complementary Probability $P_{m} /$ i:}

$$
\begin{aligned}
& \mathrm{P}_{\mathrm{m}} / \mathrm{i}=1-\mathrm{P}_{\mathrm{r}}=1-\mathrm{F}\left(\mathrm{t}_{0}\right)=1-\exp \left[-\frac{\left(1000-\mathrm{t}_{0}\right)}{200}\right] \\
& \text { if } \quad 0 \leq \mathrm{t}_{0} \leq \mathrm{t}_{\mathrm{N}}=1000
\end{aligned}
$$

We note that $\mathrm{P}_{\mathrm{m}} / \mathrm{i}$ is a non-increasing function.

\subsubsection{The Degree of Our Knowledge DOK:}

DOK is the measure of our certain knowledge (100\% probability) about the expected event, it does not include any uncertain knowledge (with probability less than $100 \%$ ):

$$
\begin{aligned}
& \text { DOK }=1-2 \cdot P_{r} \cdot\left(1-P_{r}\right)=1-2 \cdot P_{\text {rob }}(E) \cdot P_{\text {rob }}(\bar{E}) \\
& =1-2 \cdot F\left(t_{0}\right) \cdot\left[1-F\left(t_{0}\right)\right] \\
& =1-2 \cdot \exp \left[-\frac{\left(1000-t_{0}\right)}{200}\right] \cdot\left(1-\exp \left[-\frac{\left(1000-t_{0}\right)}{200}\right]\right) \\
& =1-2 \cdot \exp \left[-\frac{\left(1000-t_{0}\right)}{200}\right]+2 \cdot\left(\exp \left[-\frac{\left(1000-t_{0}\right)}{200}\right]\right)^{2} \\
& =1-2 \cdot \exp \left[-\frac{\left(1000-t_{0}\right)}{200}\right]+2 \cdot \exp \left[-\frac{2 \cdot\left(1000-t_{0}\right)}{200}\right]
\end{aligned}
$$

Which is a curve concave upward having a minimum at:

$$
\left(\mathrm{t}_{0}=861.37,0.5\right)
$$


Abdo Abou Jaoude / Journal of Mathematics and Statistics 10 (1): 1-24, 2014

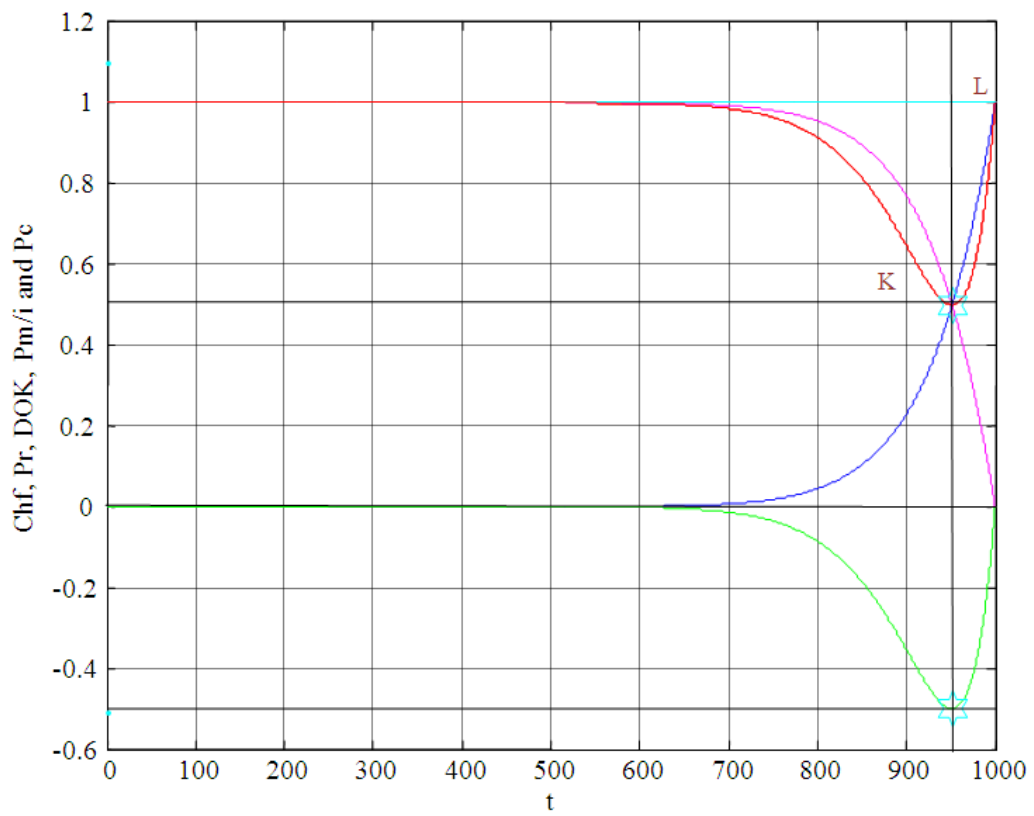

---- Chf: Chaotic factor

---- Pr: Real probability

---- DOK: Degree of our knowledge

--- Pm/i: Complementary probability

---- Pc: Probability in the set $\mathrm{C}$

Fig. 14. EKA parameters in power probability distribution

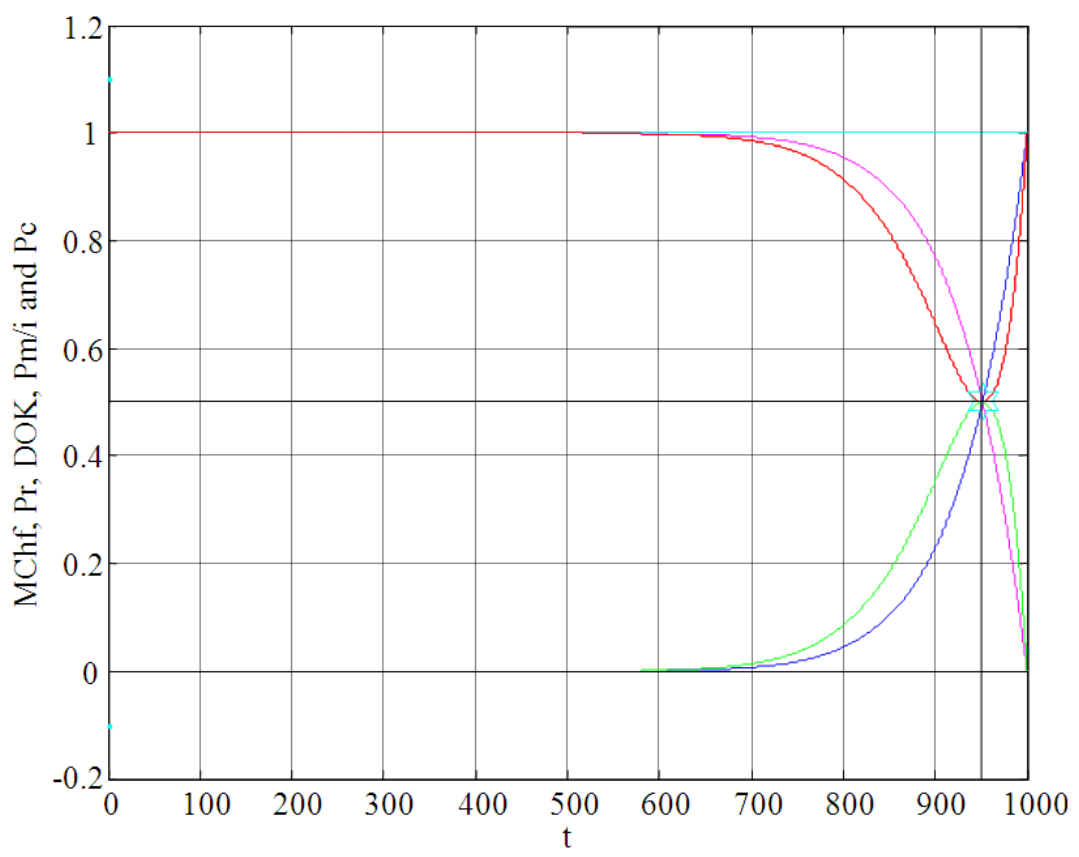

Fig. 15. EKA parameters in power cumulative distribution 


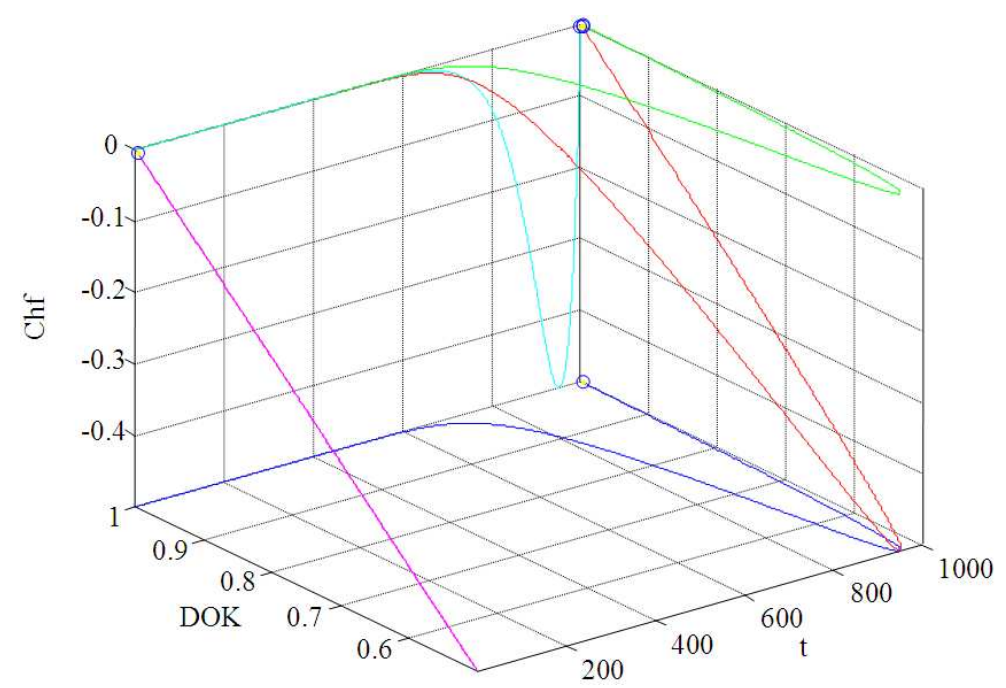

Fig. 16. DOK and Chf in terms of $t$ and of each other in power probability distribution

\subsubsection{The Chaotic Factor Chf and MChf:}

$$
\begin{aligned}
& \text { Chf }=-2 \cdot P_{\mathrm{r}} \cdot\left(1-\mathrm{P}_{\mathrm{r}}\right)=-2 \cdot \mathrm{P}_{\mathrm{rob}}(\mathrm{E}) \cdot \mathrm{P}_{\mathrm{rob}}(\overline{\mathrm{E}}) \\
& \begin{aligned}
=-2 \cdot \mathrm{F}\left(\mathrm{t}_{0}\right) \cdot\left[1-\mathrm{F}\left(\mathrm{t}_{0}\right)\right] \\
\quad=-2 \cdot \exp \left[-\frac{\left(1000-\mathrm{t}_{0}\right)}{200}\right] \cdot\left(1-\exp \left[-\frac{\left(1000-\mathrm{t}_{0}\right)}{200}\right]\right) \\
=-2 \cdot \exp \left[-\frac{\left(1000-\mathrm{t}_{0}\right)}{200}\right]+2 \cdot\left(\exp \left[-\frac{\left(1000-\mathrm{t}_{0}\right)}{200}\right]\right)^{2} \\
=-2 \cdot \exp \left[-\frac{\left(1000-\mathrm{t}_{0}\right)}{200}\right]+2 \cdot \exp \left[-\frac{2 \cdot\left(1000-\mathrm{t}_{0}\right)}{200}\right]
\end{aligned}
\end{aligned}
$$

Which is a curve concave upward having a minimum at:

$$
\left(\mathrm{t}_{0}=861.37,-0.5\right)
$$

Therefore, we can infer the magnitude of the chaotic factor MChf:

$$
\begin{aligned}
& \operatorname{MChf}\left(\mathrm{t}_{0}\right)=\left|\operatorname{Chf}\left(\mathrm{t}_{0}\right)\right|=\mid-2 \cdot \mathrm{P}_{\mathrm{r}}\left(\mathrm{t}_{0}\right) \cdot\left[1-\mathrm{P}_{\mathrm{r}}\left(\mathrm{t}_{0}\right)\right] \\
& \begin{aligned}
=2 \cdot \mathrm{P}_{\mathrm{r}}\left(\mathrm{t}_{0}\right) \cdot\left[1-\mathrm{P}_{\mathrm{r}}\left(\mathrm{t}_{0}\right)\right]=2 \cdot \mathrm{F}\left(\mathrm{t}_{0}\right) \cdot\left[1-\mathrm{F}\left(\mathrm{t}_{0}\right)\right] \\
=2 \cdot \exp \left[-\frac{\left(1000-\mathrm{t}_{0}\right)}{200}\right] \cdot\left(1-\exp \left[-\frac{\left(1000-\mathrm{t}_{0}\right)}{200}\right]\right) \\
=2 \cdot \exp \left[-\frac{\left(1000-\mathrm{t}_{0}\right)}{200}\right]-2 \cdot \exp \left[-\frac{2 \cdot\left(1000-\mathrm{t}_{0}\right)}{200}\right]
\end{aligned}
\end{aligned}
$$

Which is a curve concave downward having a maximum at:

$$
\left(\mathrm{t}_{0}=861.37,0.5\right)
$$

\subsubsection{Pc: The Probability in the Complex Set C:}

$$
\begin{aligned}
& \mathrm{Pc}^{2}=\mathrm{DOK}-\mathrm{Chf}=1-2 \cdot \exp \left[-\frac{\left(1000-\mathrm{t}_{0}\right)}{200}\right] \\
& +2 \cdot\left(\exp \left[-\frac{\left(1000-\mathrm{t}_{0}\right)}{200}\right]\right)^{2} \\
& +2 \cdot \exp \left[-\frac{\left(1000-\mathrm{t}_{0}\right)}{200}\right]-2 \cdot\left(\exp \left[-\frac{\left(1000-\mathrm{t}_{0}\right)}{200}\right]\right)^{2}=1 \\
& \Rightarrow P c=1
\end{aligned}
$$

Thus we deduce that in the set $\mathrm{C}$, we have a complete knowledge of the random variable since $\mathrm{Pc}=1$.

\subsubsection{The Intersection Point:}

$$
\begin{aligned}
& \mathrm{P}_{\mathrm{r}}\left(\mathrm{t}_{0}\right)=\mathrm{P}_{\mathrm{m}}\left(\mathrm{t}_{0}\right) / \mathrm{i} \Leftrightarrow \exp \left[-\frac{\left(1000-\mathrm{t}_{0}\right)}{200}\right] \\
& =1-\exp \left[-\frac{\left(1000-\mathrm{t}_{0}\right)}{200}\right] \Leftrightarrow 2 . \exp \left[-\frac{\left(1000-\mathrm{t}_{0}\right)}{200}\right]=1 \\
& \Leftrightarrow \exp \left[-\frac{\left(1000-\mathrm{t}_{0}\right)}{200}\right]=\frac{1}{2} \Leftrightarrow \\
& \mathrm{t}_{0}=1000+200 . \operatorname{Ln}(0.5)=861.37 \\
& \text { And } \mathrm{P}_{\mathrm{r}}\left(\mathrm{t}_{0}=861.37\right)=\exp \left[-\frac{(1000-861.37)}{200}\right]=0.5 \\
& \text { and } \mathrm{P}_{\mathrm{m}}\left(\mathrm{t}_{0}=861.37\right) / \mathrm{i}=1-\exp \left[-\frac{(1000-861.37)}{200}\right] \\
& =1-0.5=0.5
\end{aligned}
$$


Abdo Abou Jaoude / Journal of Mathematics and Statistics 10 (1): 1-24, 2014

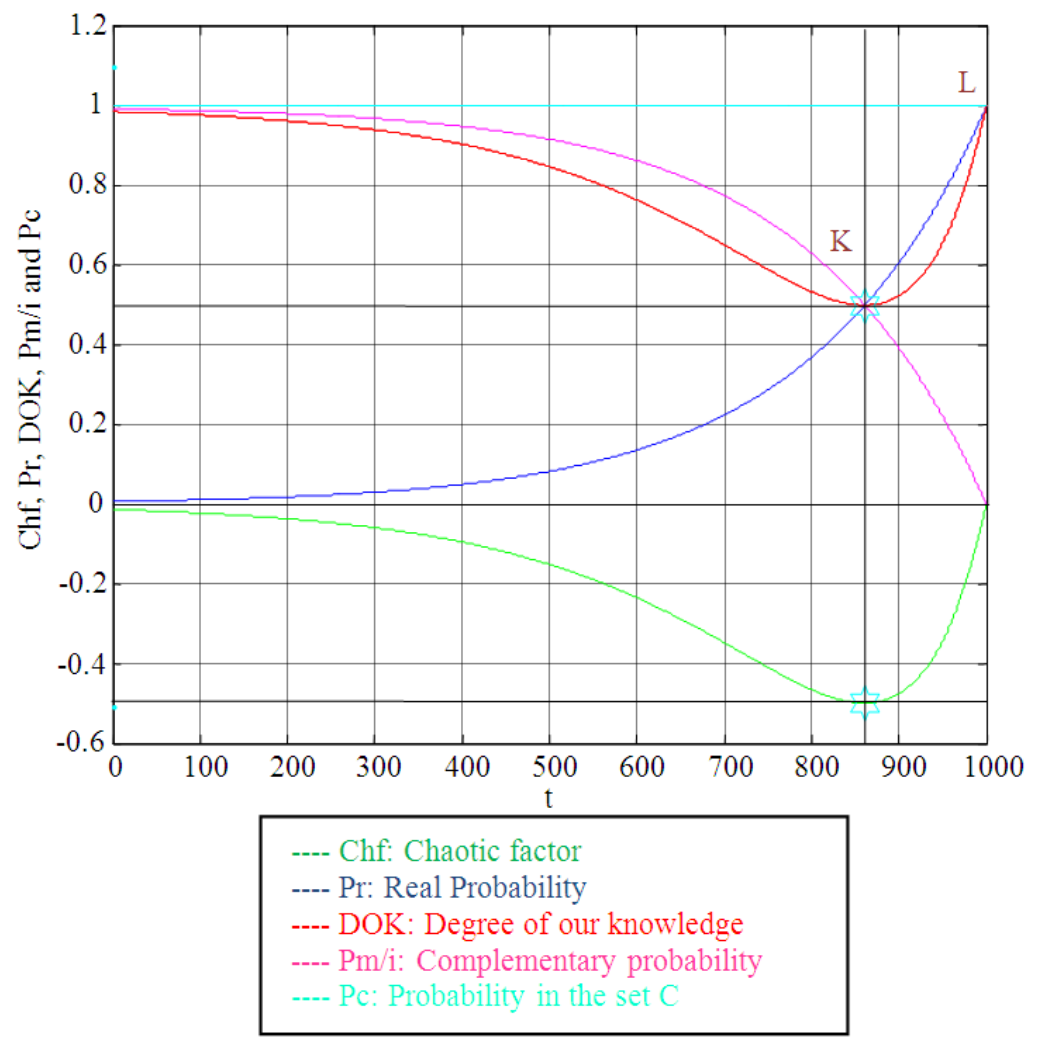

Fig. 17. EKA parameters in exponential cumulative distribution

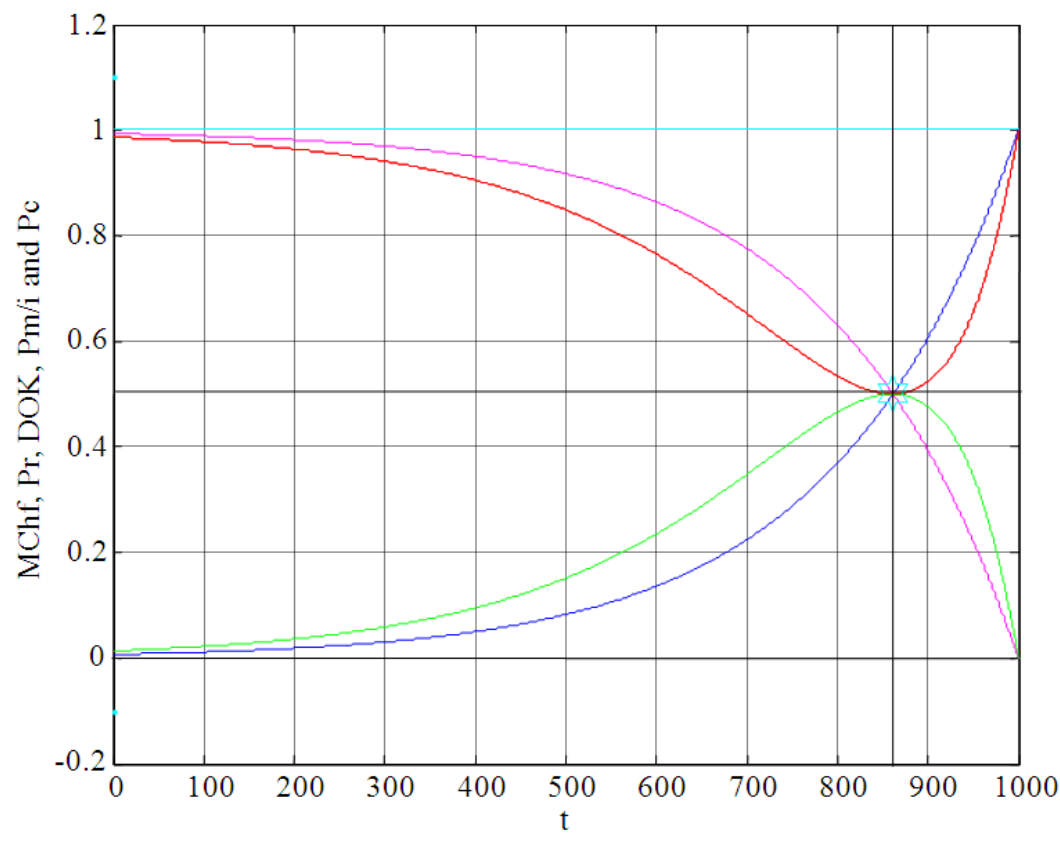

Fig. 18. EKA parameters in exponential cumulative distribution 


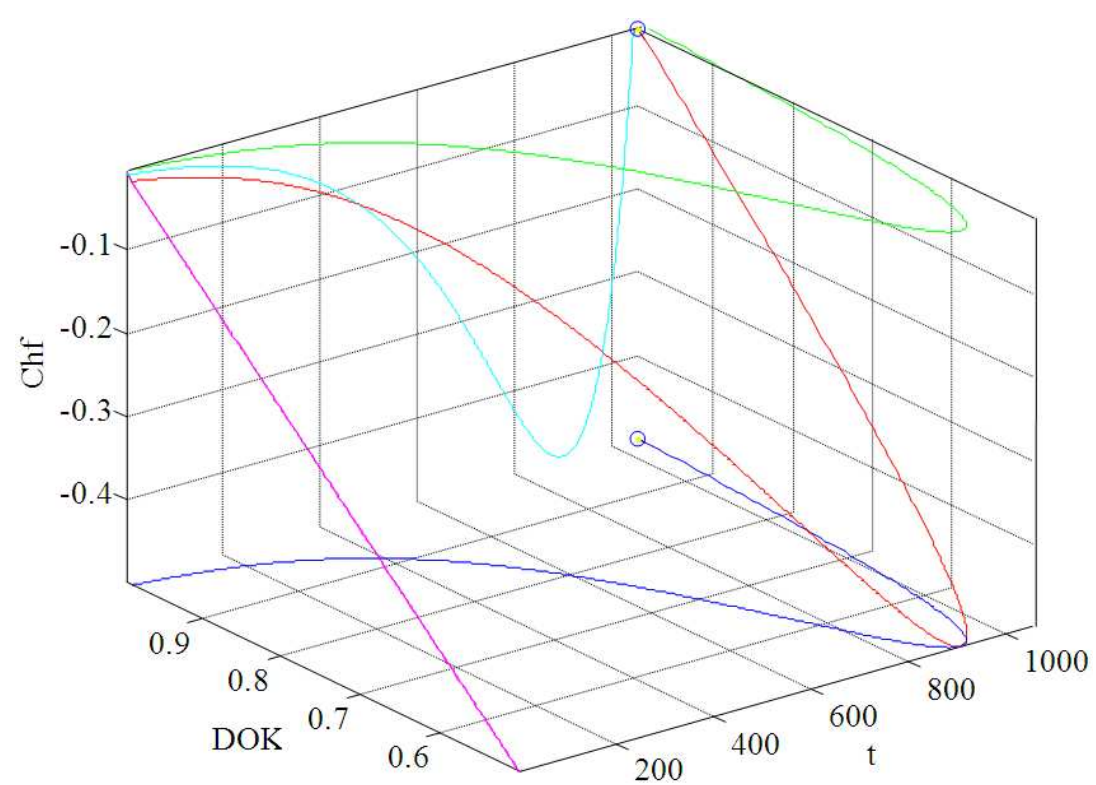

Fig. 19. DOK and Chf in terms of $t$ and of each other in exponential cumulative distribution

So $\mathrm{P}_{\mathrm{r}}\left(\mathrm{t}_{0}\right)$ and $\mathrm{P}_{\mathrm{m}}\left(\mathrm{t}_{0}\right) / \mathrm{i}$ intersect at $(861.37,0.5)$.

Moreover, the minimum of DOK and the maximum of MChf occur at $(861.37,0.5)$.

So we conclude that $\mathrm{P}_{\mathrm{r}}\left(\mathrm{t}_{0}\right), \mathrm{P}_{\mathrm{m}}\left(\mathrm{t}_{0}\right) / \mathrm{i}$, DOK and $\mathrm{MChf}$ all intersect at $(861.37,0.5)$ (Fig. 17-19).

\subsubsection{The EKA Parameters Analysis in the Prognostic of Degradation:}

In this case, we note from the figure above that the DOK is maximum (DOK=1) when MChf is minimum $(\mathrm{MChf}=0)$ (points $\mathrm{J} \& \mathrm{~L})$. Afterward, the magnitude of the chaotic factor MChf starts to increase with the decrease of DOK until it reaches 0.5 at $t_{0}=861.37$ (point K). Since the real probability $\mathrm{P}_{\mathrm{r}}$ is an exponential distribution it will intersect with DOK at the point $(861.37,0.5)$ (point $\mathrm{K}$ ). With the increase of $\mathrm{t}_{0}$, Chf and MChf return to zero and the DOK returns to 1 where we reach total damage $(D=1)$ and hence the total certain failure $\left(\mathrm{P}_{\mathrm{r}}=1\right)$ of the system (point $\mathrm{L})$. At this last point $\mathrm{L}$ the failure here is certain, $\mathrm{P}_{\mathrm{r}}\left(\mathrm{t}_{\mathrm{N}}\right)=\mathrm{t}_{\mathrm{N}} / \mathrm{t}_{\mathrm{N}}=1$ and $\operatorname{RUL}\left(\mathrm{t}_{\mathrm{N}}\right)=\mathrm{t}_{\mathrm{N}}-\mathrm{t}_{\mathrm{N}}=0$ with $\operatorname{Pc}\left(\mathrm{t}_{\mathrm{N}}\right)=$ 1 , so the logical explanation of the value $\mathrm{DOK}=1$ follows. We note that the point $\mathrm{K}$ is no more at the middle of DOK since the exponential distribution is not symmetric (Fig. 17).

\subsection{The Normal Probability Distribution:}

With a probability density function:

$$
\begin{aligned}
& f(t)=\frac{d F(t)}{d t}=\frac{1}{\sqrt{2 \pi} \sigma_{t}} \exp \left[-\frac{1}{2}\left(\frac{t-\bar{t}}{\sigma_{t}}\right)^{2}\right], \\
& \text { for }-\infty<t<\infty
\end{aligned}
$$

and a cumulative distribution function:

$$
F\left(t_{0}\right)=\int_{-\infty}^{t_{0}} f(t) d t=\int_{0}^{t_{0}} f(t) d t=\int_{0}^{t_{0}} \frac{1}{\sqrt{2 \pi} \sigma_{t}} \exp \left[-\frac{1}{2}\left(\frac{t-\bar{t}}{\sigma_{t}}\right)^{2}\right] \cdot d t,
$$

for $0 \leq \mathrm{t}_{0} \leq \mathrm{t}_{\mathrm{N}}$

We have taken the domain for the normal variable $t_{0}$ $=\left[0, \mathrm{t}_{\mathrm{N}}=1000\right], \mathrm{dt}_{0}=0.1, \overline{\mathrm{t}}=500($ Mean $)$ and $\sigma_{\mathrm{t}}=150$ (Standard deviation).

Note that:

$$
\int_{-\infty}^{+\infty} \mathrm{dF}=\int_{-\infty}^{+\infty} \mathrm{f}(\mathrm{t}) \mathrm{dt}=\int_{-\infty}^{+\infty} \frac{1}{\sqrt{2 \pi} \sigma_{\mathrm{t}}} \exp \left[-\frac{1}{2}\left(\frac{\mathrm{t}-\overline{\mathrm{t}}}{\sigma_{\mathrm{t}}}\right)^{2}\right] \cdot \mathrm{dt}=1
$$

\subsubsection{The Real Probability $P_{\mathrm{r}}$ :}

$$
\begin{aligned}
& \mathrm{P}_{\mathrm{r}}\left(\mathrm{t}_{0}\right)=\mathrm{F}\left(\mathrm{t}_{0}\right)=\int_{0}^{\mathrm{t}_{0}} \frac{1}{\sqrt{2 \pi} \sigma_{\mathrm{t}}} \exp \left[-\frac{1}{2}\left(\frac{\mathrm{t}-\overline{\mathrm{t}}}{\sigma_{\mathrm{t}}}\right)^{2}\right] . d \mathrm{t} \\
& \text { if } 0 \leq \mathrm{t}_{0} \leq \mathrm{t}_{\mathrm{N}}=1000
\end{aligned}
$$

We note that $\mathrm{P}_{\mathrm{r}}\left(\mathrm{t}_{0}\right)$ is a non-decreasing function. 


\subsubsection{The Complementary Probability $P_{m} / i$ :}

$$
\begin{aligned}
& \mathrm{P}_{\mathrm{m}}\left(\mathrm{t}_{0}\right) / \mathrm{i}=1-\mathrm{P}_{\mathrm{r}}\left(\mathrm{t}_{0}\right)=1-\mathrm{F}\left(\mathrm{t}_{0}\right) \\
& =1-\int_{0}^{\mathrm{t}_{0}} \frac{1}{\sqrt{2 \pi} \sigma_{\mathrm{t}}} \exp \left[-\frac{1}{2}\left(\frac{\mathrm{t}-\overline{\mathrm{t}}}{\sigma_{\mathrm{t}}}\right)^{2}\right] \cdot d \mathrm{t} \\
& =\int_{\mathrm{t}_{0}}^{\mathrm{t}_{\mathrm{N}}} \frac{1}{\sqrt{2 \pi} \sigma_{\mathrm{t}}} \exp \left[-\frac{1}{2}\left(\frac{\mathrm{t}-\overline{\mathrm{t}}}{\sigma_{\mathrm{t}}}\right)^{2}\right] \cdot d \mathrm{t} \\
& \quad \text { if } 0 \leq \mathrm{t}_{0} \leq \mathrm{t}_{\mathrm{N}}=1000
\end{aligned}
$$

We note that $\mathrm{P}_{\mathrm{m}}\left(\mathrm{t}_{0}\right) / \mathrm{i}$ is a non-increasing function.

\subsubsection{The Degree of Our Knowledge DOK:}

DOK is the measure of our certain knowledge ( $100 \%$ probability) about the expected event, it does not include any uncertain knowledge (with probability less than $100 \%$ ).

$$
\begin{aligned}
& \operatorname{DOK}\left(\mathrm{t}_{0}\right)=\mathrm{Pc}^{2}\left(\mathrm{t}_{0}\right)+2 \mathrm{iP}_{\mathrm{r}}\left(\mathrm{t}_{0}\right) \mathrm{P}_{\mathrm{m}}\left(\mathrm{t}_{0}\right) \\
& =1-2 \cdot \mathrm{P}_{\mathrm{rob}}(\mathrm{E}) \cdot \mathrm{P}_{\mathrm{rob}}(\overline{\mathrm{E}})=1-2 \cdot \mathrm{P}_{\mathrm{r}}\left(\mathrm{t}_{0}\right) \cdot\left[1-\mathrm{P}_{\mathrm{r}}\left(\mathrm{t}_{0}\right)\right] \\
& =1-2 \cdot \mathrm{F}\left(\mathrm{t}_{0}\right) \cdot\left[1-\mathrm{F}\left(\mathrm{t}_{0}\right)\right]=1-2 \cdot \int_{0}^{\mathrm{t}_{0}} \frac{1}{\sqrt{2 \pi} \sigma_{\mathrm{t}}} \exp \left[-\frac{1}{2}\left(\frac{\mathrm{t}-\overline{\mathrm{t}}}{\sigma_{\mathrm{t}}}\right)^{2}\right] \cdot d \mathrm{t} \\
& \times \int_{\mathrm{t}_{0}}^{\mathrm{t}_{\mathrm{N}}} \frac{1}{\sqrt{2 \pi} \sigma_{\mathrm{t}}} \exp \left[-\frac{1}{2}\left(\frac{\mathrm{t}-\overline{\mathrm{t}}}{\sigma_{\mathrm{t}}}\right)^{2}\right] \cdot d \mathrm{t} \\
& =1-2 \cdot \int_{0}^{\mathrm{t}_{0}} \frac{1}{\sqrt{2 \pi} \sigma_{\mathrm{t}}} \exp \left[-\frac{1}{2}\left(\frac{\mathrm{t}-\overline{\mathrm{t}}}{\sigma_{\mathrm{t}}}\right)^{2}\right] \cdot d \mathrm{dt} \\
& +2 \cdot\left(\int_{0}^{\mathrm{t}_{0}} \frac{1}{\sqrt{2 \pi} \sigma_{\mathrm{t}}} \exp \left[-\frac{1}{2}\left(\frac{\mathrm{t}-\overline{\mathrm{t}}}{\sigma_{\mathrm{t}}}\right)^{2}\right] \cdot d \mathrm{dt}\right)^{2}
\end{aligned}
$$

Which is a curve concave upward having a minimum at:

$$
\begin{aligned}
& \int_{0}^{\mathrm{t}_{0}} \frac{1}{\sqrt{2 \pi} \sigma_{\mathrm{t}}} \exp \left[-\frac{1}{2}\left(\frac{\mathrm{t}-\overline{\mathrm{t}}}{\sigma_{\mathrm{t}}}\right)^{2}\right] \cdot d \mathrm{t} \\
& =0.5 \Leftrightarrow \operatorname{At}\left(\mathrm{t}_{0}=\overline{\mathrm{t}}=500,0.5\right)
\end{aligned}
$$

Since the normal distribution is symmetric about the mean which is $\bar{t}=500$.

\subsubsection{The Chaotic Factor Chf and MChf:}

$$
\begin{aligned}
& \operatorname{Chf}\left(t_{0}\right)=2 i P_{r}\left(t_{0}\right) P_{m}\left(t_{0}\right)=-2 \cdot P_{r o b}(E) \cdot P_{r o b}(\bar{E}) \\
& =-2 \cdot P_{r}\left(t_{0}\right) \cdot\left[1-P_{r}\left(t_{0}\right)\right]=-2 \cdot F\left(t_{0}\right) \cdot\left[1-F\left(t_{0}\right)\right]
\end{aligned}
$$

$$
\begin{aligned}
& =-2 \cdot \int_{0}^{t_{0}} \frac{1}{\sqrt{2 \pi} \sigma_{t}} \exp \left[-\frac{1}{2}\left(\frac{\mathrm{t}-\overline{\mathrm{t}}}{\sigma_{\mathrm{t}}}\right)^{2}\right] \cdot d \mathrm{t} \\
& \times \int_{\mathrm{t}_{0}}^{\mathrm{t}_{\mathrm{N}}} \frac{1}{\sqrt{2 \pi} \sigma_{\mathrm{t}}} \exp \left[-\frac{1}{2}\left(\frac{\mathrm{t}-\overline{\mathrm{t}}}{\sigma_{\mathrm{t}}}\right)^{2}\right] \cdot d \mathrm{t} \\
& =-2 \cdot \int_{0}^{\mathrm{t}_{0}} \frac{1}{\sqrt{2 \pi} \sigma_{\mathrm{t}}} \exp \left[-\frac{1}{2}\left(\frac{\mathrm{t}-\overline{\mathrm{t}}}{\sigma_{\mathrm{t}}}\right)^{2}\right] \cdot d \mathrm{dt} \\
& +2 \cdot\left(\int_{0}^{\mathrm{t}_{0}} \frac{1}{\sqrt{2 \pi} \sigma_{\mathrm{t}}} \exp \left[-\frac{1}{2}\left(\frac{\mathrm{t}-\overline{\mathrm{t}}}{\sigma_{\mathrm{t}}}\right)^{2}\right] \cdot d \mathrm{t}\right)^{2}
\end{aligned}
$$

Which is a curve concave upward having a minimum at:

$$
\begin{aligned}
& \int_{0}^{\mathrm{t}_{0}} \frac{1}{\sqrt{2 \pi} \sigma_{\mathrm{t}}} \exp \left[-\frac{1}{2}\left(\frac{\mathrm{t}-\overline{\mathrm{t}}}{\sigma_{\mathrm{t}}}\right)^{2}\right] . \mathrm{dt} \\
& =0.5 \Leftrightarrow \operatorname{At}\left(\mathrm{t}_{0}=\overline{\mathrm{t}}=500,-0.5\right)
\end{aligned}
$$

Since the normal distribution is symmetric about the mean which is $\overline{\mathrm{t}}=500$.

Therefore, we can infer the magnitude of the chaotic factor MChf:

$$
\begin{aligned}
& \operatorname{MChf}\left(\mathrm{t}_{0}\right)=\left|\operatorname{Chf}\left(\mathrm{t}_{0}\right)\right|=\left|-2 \cdot \mathrm{P}_{\mathrm{r}}\left(\mathrm{t}_{0}\right) \cdot\left[1-\mathrm{P}_{\mathrm{r}}\left(\mathrm{t}_{0}\right)\right]\right| \\
& =2 \cdot \mathrm{P}_{\mathrm{r}}\left(\mathrm{t}_{0}\right) \cdot\left[1-\mathrm{P}_{\mathrm{r}}\left(\mathrm{t}_{0}\right)\right]=2 \cdot \mathrm{F}\left(\mathrm{t}_{0}\right) \cdot\left[1-\mathrm{F}\left(\mathrm{t}_{0}\right)\right] \\
& =2 \cdot \int_{0}^{\mathrm{t}_{0}} \frac{1}{\sqrt{2 \pi} \sigma_{\mathrm{t}}} \exp \left[-\frac{1}{2}\left(\frac{\mathrm{t}-\overline{\mathrm{t}}}{\sigma_{\mathrm{t}}}\right)^{2}\right] \cdot d \mathrm{dt} \\
& \times \int_{\mathrm{t}_{0}}^{\mathrm{t}_{\mathrm{N}}} \frac{1}{\sqrt{2 \pi} \sigma_{\mathrm{t}}} \exp \left[-\frac{1}{2}\left(\frac{\mathrm{t}-\overline{\mathrm{t}}}{\sigma_{\mathrm{t}}}\right)^{2}\right] \cdot d \mathrm{t} \\
& =2 \cdot \int_{0}^{\mathrm{t}_{0}} \frac{1}{\sqrt{2 \pi} \sigma_{\mathrm{t}}} \exp \left[-\frac{1}{2}\left(\frac{\mathrm{t}-\overline{\mathrm{t}}}{\sigma_{\mathrm{t}}}\right)^{2}\right] \cdot d \mathrm{dt} \\
& -2 \cdot\left(\int_{0}^{\mathrm{t}_{0}} \frac{1}{\sqrt{2 \pi} \sigma_{\mathrm{t}}} \exp \left[-\frac{1}{2}\left(\frac{\mathrm{t}-\overline{\mathrm{t}}}{\sigma_{\mathrm{t}}}\right)^{2}\right] \cdot d \mathrm{dt}\right)^{2}
\end{aligned}
$$

Which is a curve concave downward having a maximum at:

$$
\begin{aligned}
& \int_{0}^{\mathrm{t}_{0}} \frac{1}{\sqrt{2 \pi} \sigma_{\mathrm{t}}} \exp \left[-\frac{1}{2}\left(\frac{\mathrm{t}-\overline{\mathrm{t}}}{\sigma_{\mathrm{t}}}\right)^{2}\right] \cdot d \mathrm{t} \\
& =0.5 \Leftrightarrow \operatorname{At}\left(\mathrm{t}_{0}=\overline{\mathrm{t}}=500,0.5\right)
\end{aligned}
$$

Since the normal distribution is symmetric about the mean which is $\overline{\mathrm{t}}=500$. 


\subsubsection{Pc: The Probability in the Complex Set C:}

$$
\begin{aligned}
& \operatorname{Pc}^{2}\left(\mathrm{t}_{0}\right)=\operatorname{DOK}\left(\mathrm{t}_{0}\right)-\operatorname{Chf}\left(\mathrm{t}_{0}\right) \\
& =1-2 \cdot \int_{0}^{\mathrm{t}_{0}} \frac{1}{\sqrt{2 \pi} \sigma_{\mathrm{t}}} \exp \left[-\frac{1}{2}\left(\frac{\mathrm{t}-\overline{\mathrm{t}}}{\sigma_{\mathrm{t}}}\right)^{2}\right] \cdot d \mathrm{dt} \\
& \times \int_{\mathrm{t}_{0}}^{\mathrm{t}_{\mathrm{N}}} \frac{1}{\sqrt{2 \pi} \sigma_{\mathrm{t}}} \exp \left[-\frac{1}{2}\left(\frac{\mathrm{t}-\overline{\mathrm{t}}}{\sigma_{\mathrm{t}}}\right)^{2}\right] \cdot d \mathrm{t} \\
& +2 \cdot \int_{0}^{\mathrm{t}_{0}} \frac{1}{\sqrt{2 \pi} \sigma_{\mathrm{t}}} \exp \left[-\frac{1}{2}\left(\frac{\mathrm{t}-\overline{\mathrm{t}}}{\sigma_{\mathrm{t}}}\right)^{2}\right] \cdot d \mathrm{t} \\
& \times \int_{\mathrm{t}_{0}}^{\mathrm{t}_{\mathrm{N}}} \frac{1}{\sqrt{2 \pi} \sigma_{\mathrm{t}}} \exp \left[-\frac{1}{2}\left(\frac{\mathrm{t}-\overline{\mathrm{t}}}{\sigma_{\mathrm{t}}}\right)^{2}\right] \cdot d \mathrm{t}=1 \\
& \Rightarrow \operatorname{Pc}\left(\mathrm{t}_{0}\right)=1
\end{aligned}
$$

Thus we deduce that in the set $\mathrm{C}$, we have a complete knowledge of the random variable since $\mathrm{Pc}=1$.

\subsubsection{The Intersection Point:}

$$
\begin{aligned}
& \mathrm{P}_{\mathrm{r}}\left(\mathrm{t}_{0}\right)=\mathrm{P}_{\mathrm{m}}\left(\mathrm{t}_{0}\right) / \mathrm{i} \Leftrightarrow \int_{0}^{\mathrm{t}_{0}} \frac{1}{\sqrt{2 \pi} \sigma_{\mathrm{t}}} \exp \left[-\frac{1}{2}\left(\frac{\mathrm{t}-\overline{\mathrm{t}}}{\sigma_{\mathrm{t}}}\right)^{2}\right] \cdot d \mathrm{t} \\
& =1-\int_{0}^{\mathrm{t}_{0}} \frac{1}{\sqrt{2 \pi} \sigma_{\mathrm{t}}} \exp \left[-\frac{1}{2}\left(\frac{\mathrm{t}-\overline{\mathrm{t}}}{\sigma_{\mathrm{t}}}\right)^{2}\right] \cdot d \mathrm{t} \\
& \Leftrightarrow 2 \cdot \int_{0}^{\mathrm{t}_{0}} \frac{1}{\sqrt{2 \pi} \sigma_{\mathrm{t}}} \exp \left[-\frac{1}{2}\left(\frac{\mathrm{t}-\overline{\mathrm{t}}}{\sigma_{\mathrm{t}}}\right)^{2}\right] \cdot d \mathrm{t}=1 \\
& \Leftrightarrow \int_{0}^{\mathrm{t}_{0}} \frac{1}{\sqrt{2 \pi} \sigma_{\mathrm{t}}} \exp \left[-\frac{1}{2}\left(\frac{\mathrm{t}-\overline{\mathrm{t}}}{\sigma_{\mathrm{t}}}\right)^{2}\right] \cdot \mathrm{dt},=\frac{1}{2}=0.5 \\
& \Leftrightarrow \mathrm{t}_{0}=\overline{\mathrm{t}}=500 \\
& \text { and } \mathrm{P}_{\mathrm{r}}\left(\mathrm{t}_{0}=\overline{\mathrm{t}}=500\right)=0.5 \\
& \text { and } \mathrm{P}_{\mathrm{m}}\left(\mathrm{t}_{0}=\overline{\mathrm{t}}=500\right) / \mathrm{i}=1-0.5=0.5
\end{aligned}
$$

So $\mathrm{P}_{\mathrm{r}}\left(\mathrm{t}_{0}\right)$ and $\mathrm{P}_{\mathrm{m}}\left(\mathrm{t}_{0}\right) / \mathrm{i}$ intersect at $(500,0.5)$.

Moreover, the minimum of DOK and the maximum of MChf occur at $(500,0.5)$.

So we conclude that $\mathrm{P}_{\mathrm{r}}\left(\mathrm{t}_{0}\right), \mathrm{P}_{\mathrm{m}}\left(\mathrm{t}_{0}\right) / \mathrm{i}$, DOK and MChf all intersect at $(500,0.5)$ (Fig. 20-22).

\subsubsection{The EKA Parameters Analysis in the Prognostic of Degradation:}

In this case, we note from the figure that the DOK is maximum ( $\mathrm{DOK}=1$ ) when $\mathrm{MChf}$ is minimum
$(\mathrm{MChf}=0)$ (points $\mathbf{J} \& \mathrm{~L})$. Afterward, the magnitude of the chaotic factor MChf starts to increase with the decrease of DOK until it reaches 0.5 at $\mathrm{t}_{0}=500$ (point $\mathrm{K})$. Since the real probability $\mathrm{P}_{\mathrm{r}}$ is a normal distribution it will intersect with DOK at the point $(500,0.5)$ (point $\mathrm{K})$. With the increase of $\mathrm{t}_{0}$, Chf and MChf return to zero and the DOK returns to 1 where we reach total damage $(D=1)$ and hence the total certain failure $\left(\mathrm{P}_{\mathrm{r}}=1\right)$ of the system (point $\mathrm{L}$ ). At this last point $L$ the failure here is certain, $P_{r}\left(t_{N}\right)=t_{N} / t_{N}=1$ and $\operatorname{RUL}\left(\mathrm{t}_{\mathrm{N}}\right)=\mathrm{t}_{\mathrm{N}}-\mathrm{t}_{\mathrm{N}}=0$ with $\operatorname{Pc}\left(\mathrm{t}_{\mathrm{N}}\right)=1$, so the logical explanation of the value $\mathrm{DOK}=1$ follows. We note that the point $\mathrm{K}$ is at the middle of DOK since the normal distribution is symmetric (Fig. 20).

\subsection{The Lognormal Probability Distribution:}

With a probability density function:

$$
\begin{aligned}
& \mathrm{f}(\mathrm{t})=\frac{\mathrm{dF}(\mathrm{t})}{\mathrm{dt}}=\frac{1}{\sqrt{2 \pi} \sigma_{\mathrm{t}} \mathrm{t}} \exp \left[-\frac{1}{2}\left(\frac{\operatorname{Ln}(\mathrm{t})-\overline{\mathrm{t}}}{\sigma_{\mathrm{t}}}\right)^{2}\right], \\
& \text { for } 0<\mathrm{t}<\infty
\end{aligned}
$$

and a cumulative distribution function:

$$
\begin{aligned}
& \mathrm{F}\left(\mathrm{t}_{0}\right)=\int_{0}^{\mathrm{t}_{0}} \mathrm{f}(\mathrm{t}) \mathrm{dt}=\int_{0}^{\mathrm{t}_{0}} \frac{1}{\sqrt{2 \pi} \sigma_{\mathrm{t}} \mathrm{t}} \exp \left[-\frac{1}{2}\left(\frac{\operatorname{Ln}(\mathrm{t})-\overline{\mathrm{t}}}{\sigma_{\mathrm{t}}}\right)^{2}\right] \mathrm{dt} \\
& \text { for } 0 \leq \mathrm{t}_{0} \leq \mathrm{t}_{\mathrm{N}}
\end{aligned}
$$

We have taken the domain for the lognormal variable $\mathrm{t}_{0}=\left[0, \mathrm{t}_{\mathrm{N}}=1000\right], \mathrm{dt}_{0}=0.1, \overline{\mathrm{t}}=5.3$ (mean) and $\sigma_{\mathrm{t}}=0.7$ (standard deviation).

Note that:

$$
\int_{0}^{+\infty} \mathrm{dF}=\int_{0}^{+\infty} \mathrm{f}(\mathrm{t}) \mathrm{dt}=\int_{0}^{+\infty} \frac{1}{\sqrt{2 \pi} \sigma_{\mathrm{t}} \mathrm{t}} \exp \left[-\frac{1}{2}\left(\frac{\operatorname{Ln}(\mathrm{t})-\overline{\mathrm{t}}}{\sigma_{\mathrm{t}}}\right)^{2}\right] \cdot \mathrm{dt}=1
$$

\subsubsection{The Real Probability $P_{r}$ :}

$$
\begin{aligned}
& \mathrm{P}_{\mathrm{r}}\left(\mathrm{t}_{0}\right)=\mathrm{F}\left(\mathrm{t}_{0}\right)=\int_{0}^{\mathrm{t}_{0}} \frac{1}{\sqrt{2 \pi} \sigma_{\mathrm{t}} \mathrm{t}} \exp \left[-\frac{1}{2}\left(\frac{\operatorname{Ln}(\mathrm{t})-\overline{\mathrm{t}}}{\sigma_{\mathrm{t}}}\right)^{2}\right] \cdot d \mathrm{t} \\
& \text { if } 0 \leq \mathrm{t}_{0} \leq \mathrm{t}_{\mathrm{N}}=1000
\end{aligned}
$$

We note that $\mathrm{P}_{\mathrm{r}}\left(\mathrm{t}_{0}\right)$ is a non-decreasing function. 
Abdo Abou Jaoude / Journal of Mathematics and Statistics 10 (1): 1-24, 2014

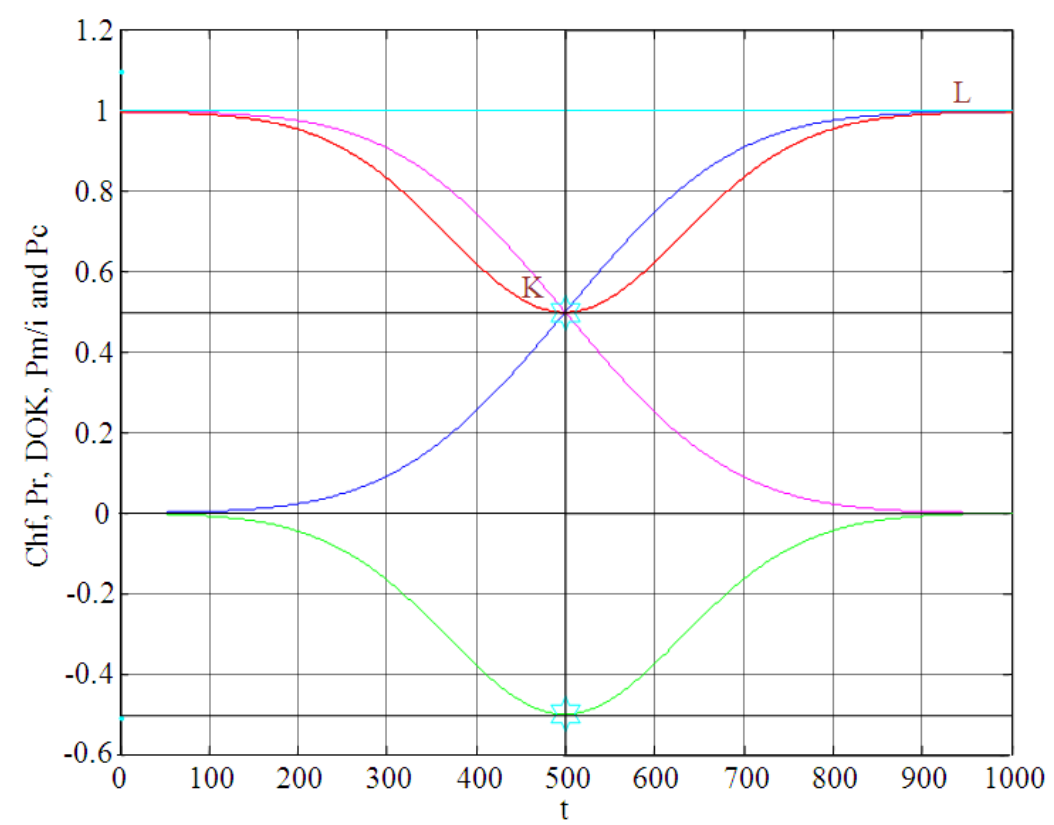

--- Chf: Chaotic factor

--- Pr: Real probability

---- DOK: Degree of our knowledge

--- Pm/i: Complementary probability

--- Pc: Probability in the set C

Fig. 20. EKA parameters in normal probability distribution

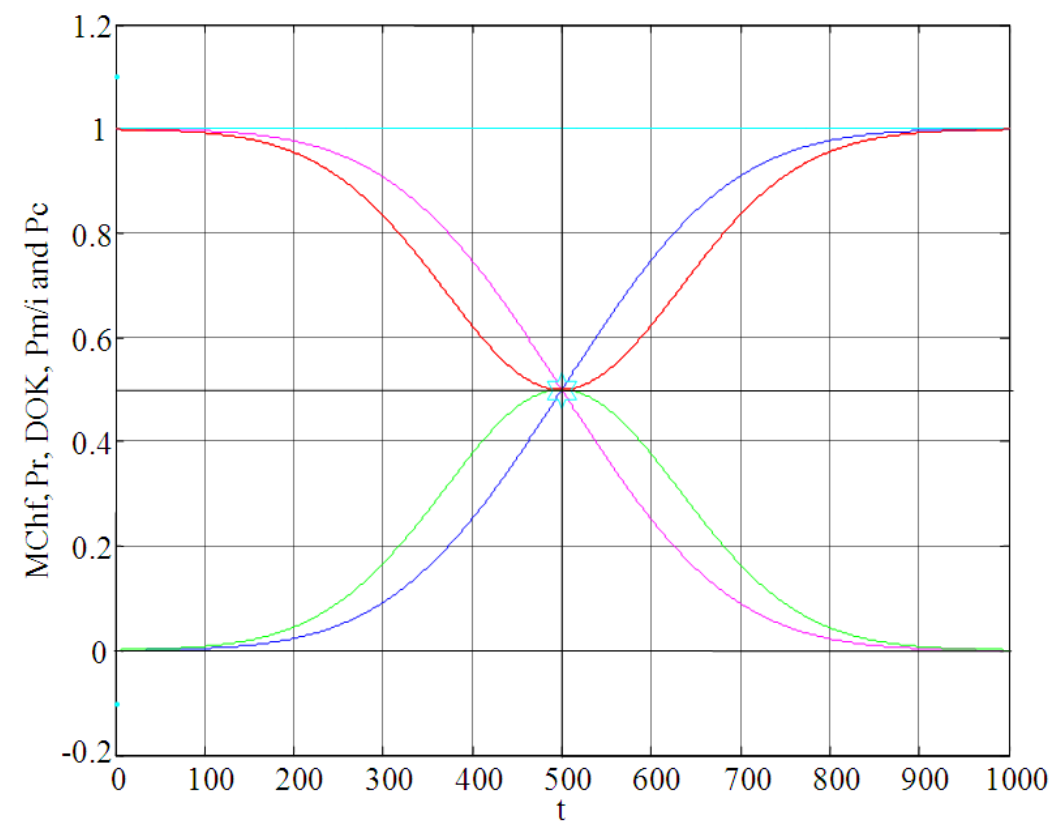

Fig. 21. EKA parameters in normal probability distribution 


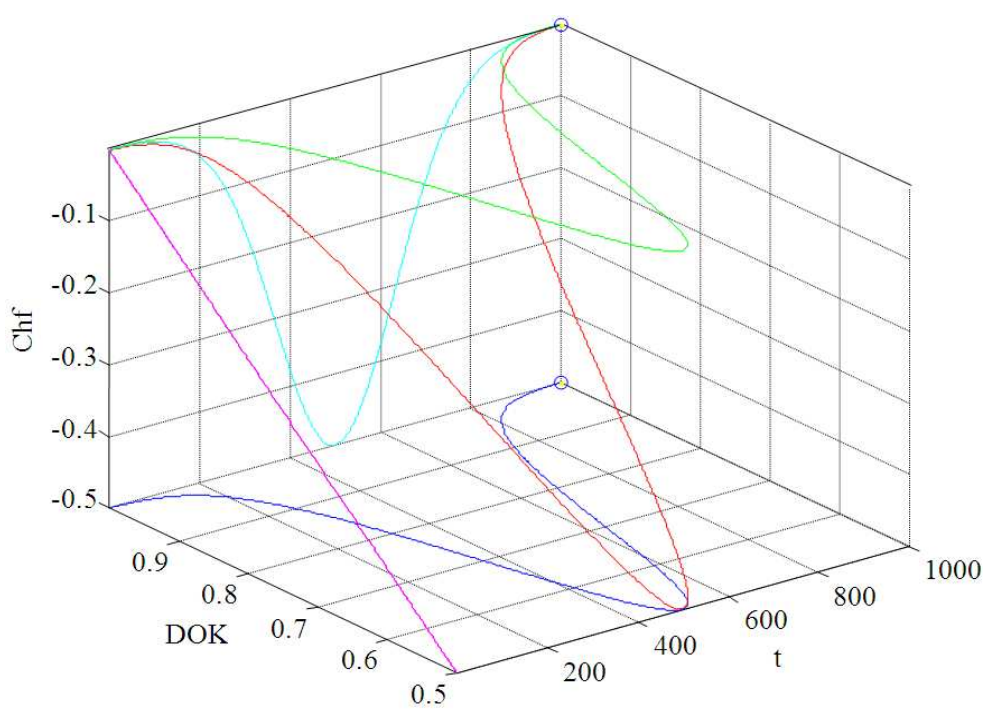

Fig. 22. DOK and $\mathrm{Chf}$ in terms of $\mathrm{t}$ and of each other in normal probability distribution

\subsubsection{The Complementary Probability $P_{m} / i$ :}

$$
\begin{aligned}
& \mathrm{P}_{\mathrm{m}}\left(\mathrm{t}_{0}\right) / \mathrm{i}=1-\mathrm{P}_{\mathrm{r}}\left(\mathrm{t}_{0}\right)=1-\mathrm{F}\left(\mathrm{t}_{0}\right) \\
& =1-\int_{0}^{\mathrm{t}_{0}} \frac{1}{\sqrt{2 \pi} \sigma_{\mathrm{t}} \mathrm{t}} \exp \left[-\frac{1}{2}\left(\frac{\operatorname{Ln}(\mathrm{t})-\overline{\mathrm{t}}}{\sigma_{\mathrm{t}}}\right)^{2}\right] \cdot d \mathrm{t} \\
& =\int_{\mathrm{t}_{0}}^{\mathrm{t}_{\mathrm{N}}} \frac{1}{\sqrt{2 \pi} \sigma_{\mathrm{t}} \mathrm{t}} \exp \left[-\frac{1}{2}\left(\frac{\operatorname{Ln}(\mathrm{t})-\overline{\mathrm{t}}}{\sigma_{\mathrm{t}}}\right)^{2}\right] \cdot d \mathrm{~d} \\
& \text { if } 0 \leq \mathrm{t}_{0} \leq \mathrm{t}_{\mathrm{N}}=1000
\end{aligned}
$$

We note that $\mathrm{P}_{\mathrm{m}}\left(\mathrm{t}_{0}\right) / \mathrm{i}$ is a non-increasing function.

\subsubsection{The Degree of Our Knowledge DOK:}

DOK is the measure of our certain knowledge ( $100 \%$ probability) about the expected event, it does not include any uncertain knowledge (with probability less than $100 \%$ ):

$$
\begin{aligned}
& \operatorname{DOK}\left(\mathrm{t}_{0}\right)=\operatorname{Pc}^{2}\left(\mathrm{t}_{0}\right)+2 \mathrm{iP}_{\mathrm{r}}\left(\mathrm{t}_{0}\right) \mathrm{P}_{\mathrm{m}}\left(\mathrm{t}_{0}\right) \\
& =1-2 \cdot \mathrm{P}_{\mathrm{rob}}(\mathrm{E}) \cdot \mathrm{P}_{\mathrm{rob}}(\overline{\mathrm{E}})=1-2 \cdot \mathrm{P}_{\mathrm{r}}\left(\mathrm{t}_{0}\right) \cdot\left[1-\mathrm{P}_{\mathrm{r}}\left(\mathrm{t}_{0}\right)\right] \\
& =1-2 \cdot \mathrm{F}\left(\mathrm{t}_{0}\right) \cdot\left[1-\mathrm{F}\left(\mathrm{t}_{0}\right)\right] \\
& =1-2 \cdot \int_{0}^{\mathrm{t}_{0}} \frac{1}{\sqrt{2 \pi} \sigma_{\mathrm{t}} \mathrm{t}} \exp \left[-\frac{1}{2}\left(\frac{\operatorname{Ln}(\mathrm{t})-\overline{\mathrm{t}}}{\sigma_{\mathrm{t}}}\right)^{2}\right] \cdot d \mathrm{dt} \\
& \quad \times \int_{\mathrm{t}_{0}}^{\mathrm{t}_{\mathrm{N}}} \frac{1}{\sqrt{2 \pi} \sigma_{\mathrm{t}} \mathrm{t}} \exp \left[-\frac{1}{2}\left(\frac{\operatorname{Ln}(\mathrm{t})-\overline{\mathrm{t}}}{\sigma_{\mathrm{t}}}\right)^{2}\right] \cdot d \mathrm{t} \\
& =1-2 \cdot \int_{0}^{\mathrm{t}_{0}} \frac{1}{\sqrt{2 \pi} \sigma_{\mathrm{t}} \mathrm{t}} \exp \left[-\frac{1}{2}\left(\frac{\operatorname{Ln}(\mathrm{t})-\overline{\mathrm{t}}}{\sigma_{\mathrm{t}}}\right)^{2}\right] \cdot \mathrm{dt}
\end{aligned}
$$

$$
+2 \cdot\left(\int_{0}^{t_{0}} \frac{1}{\sqrt{2 \pi} \sigma_{t} t} \exp \left[-\frac{1}{2}\left(\frac{\operatorname{Ln}(t)-\bar{t}}{\sigma_{t}}\right)^{2}\right] \cdot d t\right)^{2}
$$

which is a curve concave upward having a minimum at:

$$
\begin{aligned}
& \int_{0}^{\mathrm{t}_{0}} \frac{1}{\sqrt{2 \pi} \sigma_{\mathrm{t}} \mathrm{t}} \exp \left[-\frac{1}{2}\left(\frac{\operatorname{Ln}(\mathrm{t})-\overline{\mathrm{t}}}{\sigma_{\mathrm{t}}}\right)^{2}\right] \cdot d \mathrm{t} \\
& =0.5 \Leftrightarrow \text { At }\left(\mathrm{t}_{0}=200.34,0.5\right)
\end{aligned}
$$

Notice that $\operatorname{Ln}(200.34)=5.3=\bar{t}$ which is the mean of the distribution and equivalently $\exp (\overline{\mathrm{t}}=5.3)=200.34$. This is conformed to the lognormal distribution.

\subsubsection{The Chaotic Factor Chf and MChf:}

$$
\begin{aligned}
& \operatorname{Chf}\left(\mathrm{t}_{0}\right)=2 \mathrm{iP}_{\mathrm{r}}\left(\mathrm{t}_{0}\right) \mathrm{P}_{\mathrm{m}}\left(\mathrm{t}_{0}\right)=-2 \cdot \mathrm{P}_{\mathrm{rob}}(\mathrm{E}) \cdot \mathrm{P}_{\mathrm{rob}}(\overline{\mathrm{E}}) \\
& =-2 \cdot \mathrm{P}_{\mathrm{r}}\left(\mathrm{t}_{0}\right) \cdot\left[1-\mathrm{P}_{\mathrm{r}}\left(\mathrm{t}_{0}\right)\right]=-2 \cdot \mathrm{F}\left(\mathrm{t}_{0}\right) \cdot\left[1-\mathrm{F}\left(\mathrm{t}_{0}\right)\right] \\
& =-2 \cdot \int_{0}^{\mathrm{t}_{0}} \frac{1}{\sqrt{2 \pi} \sigma_{\mathrm{t}} \mathrm{t}} \exp \left[-\frac{1}{2}\left(\frac{\operatorname{Ln}(\mathrm{t})-\overline{\mathrm{t}}}{\sigma_{\mathrm{t}}}\right)^{2}\right] \cdot d \mathrm{t} \\
& \quad \times \int_{\mathrm{t}_{0}}^{\mathrm{t}_{\mathrm{N}}} \frac{1}{\sqrt{2 \pi} \sigma_{\mathrm{t}} \mathrm{t}} \exp \left[-\frac{1}{2}\left(\frac{\operatorname{Ln}(\mathrm{t})-\overline{\mathrm{t}}}{\sigma_{\mathrm{t}}}\right)^{2}\right] \cdot d \mathrm{t} \\
& =-2 \cdot \int_{0}^{\mathrm{t}_{0}} \frac{1}{\sqrt{2 \pi} \sigma_{\mathrm{t}} \mathrm{t}} \exp \left[-\frac{1}{2}\left(\frac{\operatorname{Ln}(\mathrm{t})-\overline{\mathrm{t}}}{\sigma_{\mathrm{t}}}\right)^{2}\right] \cdot d \mathrm{t} \\
& +2 \cdot\left(\int_{0}^{\mathrm{t}_{0}} \frac{1}{\sqrt{2 \pi} \sigma_{\mathrm{t}} \mathrm{t}} \exp \left[-\frac{1}{2}\left(\frac{\operatorname{Ln}(\mathrm{t})-\overline{\mathrm{t}}}{\sigma_{\mathrm{t}}}\right)^{2}\right] \cdot d \mathrm{dt}\right)^{2}
\end{aligned}
$$


which is a curve concave upward having a minimum at:

$$
\begin{aligned}
& \int_{0}^{\mathrm{t}_{0}} \frac{1}{\sqrt{2 \pi} \sigma_{\mathrm{t}} \mathrm{t}} \exp \left[-\frac{1}{2}\left(\frac{\operatorname{Ln}(\mathrm{t})-\overline{\mathrm{t}}}{\sigma_{\mathrm{t}}}\right)^{2}\right] \cdot \mathrm{dt}=0.5 \\
& \Leftrightarrow \operatorname{At}\left(\mathrm{t}_{0}=\exp (\overline{\mathrm{t}}=5.3)=200.34,-0.5\right)
\end{aligned}
$$

Therefore, we can infer the magnitude of the chaotic factor MChf:

$$
\begin{aligned}
& \operatorname{MChf}\left(\mathrm{t}_{0}\right)=\left|\operatorname{Chf}\left(\mathrm{t}_{0}\right)\right|=\mid-2 \cdot \mathrm{P}_{\mathrm{r}}\left(\mathrm{t}_{0}\right) \cdot\left[1-\mathrm{P}_{\mathrm{r}}\left(\mathrm{t}_{0}\right)\right] \\
& =2 \cdot \mathrm{P}_{\mathrm{r}}\left(\mathrm{t}_{0}\right) \cdot\left[1-\mathrm{P}_{\mathrm{r}}\left(\mathrm{t}_{0}\right)\right]=2 \cdot \mathrm{F}\left(\mathrm{t}_{0}\right) \cdot\left[1-\mathrm{F}\left(\mathrm{t}_{0}\right)\right] \\
& =2 \cdot \int_{0}^{\mathrm{t}_{0}} \frac{1}{\sqrt{2 \pi} \sigma_{\mathrm{t}} \mathrm{t}} \exp \left[-\frac{1}{2}\left(\frac{\operatorname{Ln}(\mathrm{t})-\overline{\mathrm{t}}}{\sigma_{\mathrm{t}}}\right)^{2}\right] \cdot d \mathrm{dt} \\
& \times \int_{\mathrm{t}_{0}}^{\mathrm{t}_{\mathrm{N}}} \frac{1}{\sqrt{2 \pi} \sigma_{\mathrm{t}} \mathrm{t}} \exp \left[-\frac{1}{2}\left(\frac{\operatorname{Ln}(\mathrm{t})-\overline{\mathrm{t}}}{\sigma_{\mathrm{t}}}\right)^{2}\right] \cdot d \mathrm{~d} \\
& =2 \cdot \int_{0}^{\mathrm{t}_{0}} \frac{1}{\sqrt{2 \pi} \sigma_{\mathrm{t}} \mathrm{t}} \exp \left[-\frac{1}{2}\left(\frac{\operatorname{Ln}(\mathrm{t})-\overline{\mathrm{t}}}{\sigma_{\mathrm{t}}}\right)^{2}\right] \cdot d \mathrm{dt} \\
& -2 \cdot\left(\int_{0}^{\mathrm{t}_{0}} \frac{1}{\sqrt{2 \pi} \sigma_{\mathrm{t}} \mathrm{t}} \exp \left[-\frac{1}{2}\left(\frac{\operatorname{Ln}(\mathrm{t})-\overline{\mathrm{t}}}{\sigma_{\mathrm{t}}}\right)^{2}\right] \cdot d \mathrm{dt}\right)^{2}
\end{aligned}
$$

which is a curve concave downward having a maximum at:

$$
\begin{aligned}
& \int_{0}^{\mathrm{t}_{0}} \frac{1}{\sqrt{2 \pi} \sigma_{\mathrm{t}} \mathrm{t}} \exp \left[-\frac{1}{2}\left(\frac{\operatorname{Ln}(\mathrm{t})-\overline{\mathrm{t}}}{\sigma_{\mathrm{t}}}\right)^{2}\right] \cdot d \mathrm{t}=0.5 \\
& \Leftrightarrow \text { At }\left(\mathrm{t}_{0}=\exp (\overline{\mathrm{t}}=5.3)=200.34,0.5\right)
\end{aligned}
$$

\subsubsection{Pc: Probability in the Complex Set C:}

$$
\begin{gathered}
\operatorname{Pc}^{2}\left(\mathrm{t}_{0}\right)=\operatorname{DOK}\left(\mathrm{t}_{0}\right)-\operatorname{Chf}\left(\mathrm{t}_{0}\right) \\
=1-2 \cdot \int_{0}^{\mathrm{t}_{0}} \frac{1}{\sqrt{2 \pi} \sigma_{\mathrm{t}} \mathrm{t}} \exp \left[-\frac{1}{2}\left(\frac{\operatorname{Ln}(\mathrm{t})-\overline{\mathrm{t}}}{\sigma_{\mathrm{t}}}\right)^{2}\right] \cdot d \mathrm{dt} \\
\quad \times \int_{\mathrm{t}_{0}}^{\mathrm{t}_{\mathrm{N}}} \frac{1}{\sqrt{2 \pi} \sigma_{\mathrm{t}} \mathrm{t}} \exp \left[-\frac{1}{2}\left(\frac{\operatorname{Ln}(\mathrm{t})-\overline{\mathrm{t}}}{\sigma_{\mathrm{t}}}\right)^{2}\right] \cdot d \mathrm{t} \\
+2 \cdot \int_{0}^{\mathrm{t}_{0}} \frac{1}{\sqrt{2 \pi} \sigma_{\mathrm{t}} \mathrm{t}} \exp \left[-\frac{1}{2}\left(\frac{\operatorname{Ln}(\mathrm{t})-\overline{\mathrm{t}}}{\sigma_{\mathrm{t}}}\right)^{2}\right] \cdot \mathrm{dt} \\
\times \int_{\mathrm{t}_{0}}^{\mathrm{t}_{\mathrm{N}}} \frac{1}{\sqrt{2 \pi} \sigma_{\mathrm{t}} \mathrm{t}} \exp \left[-\frac{1}{2}\left(\frac{\operatorname{Ln}(\mathrm{t})-\overline{\mathrm{t}}}{\sigma_{\mathrm{t}}}\right)^{2}\right] \cdot \mathrm{dt}=1 \Rightarrow \operatorname{Pc}\left(\mathrm{t}_{0}\right)=1
\end{gathered}
$$

Thus we deduce that in the set $\mathrm{C}$, we have a complete knowledge of the random variable since $\mathrm{Pc}=1$.

\subsubsection{The Intersection Point:}

$$
\begin{aligned}
& \mathrm{P}_{\mathrm{r}}\left(\mathrm{t}_{0}\right)=\mathrm{P}_{\mathrm{m}}\left(\mathrm{t}_{0}\right) / \mathrm{i} \Leftrightarrow \int_{0}^{\mathrm{t}_{0}} \frac{1}{\sqrt{2 \pi} \sigma_{\mathrm{t}} \mathrm{t}} \exp \left[-\frac{1}{2}\left(\frac{\operatorname{Ln}(\mathrm{t})-\overline{\mathrm{t}}}{\sigma_{\mathrm{t}}}\right)^{2}\right] \cdot d \mathrm{dt} \\
& =1-\int_{0}^{\mathrm{t}_{0}} \frac{1}{\sqrt{2 \pi} \sigma_{\mathrm{t}} \mathrm{t}} \exp \left[-\frac{1}{2}\left(\frac{\operatorname{Ln}(\mathrm{t})-\overline{\mathrm{t}}}{\sigma_{\mathrm{t}}}\right)^{2}\right] \cdot d \mathrm{~d} \\
& \Leftrightarrow 2 \cdot \int_{0}^{\mathrm{t}_{0}} \frac{1}{\sqrt{2 \pi} \sigma_{\mathrm{t}} \mathrm{t}} \exp \left[-\frac{1}{2}\left(\frac{\operatorname{Ln}(\mathrm{t})-\overline{\mathrm{t}}}{\sigma_{\mathrm{t}}}\right)^{2}\right] \cdot d \mathrm{dt}=1 \\
& \Leftrightarrow \int_{0}^{\mathrm{t}_{0}} \frac{1}{\sqrt{2 \pi} \sigma_{\mathrm{t}} \mathrm{t}} \exp \left[-\frac{1}{2}\left(\frac{\operatorname{Ln}(\mathrm{t})-\overline{\mathrm{t}}}{\sigma_{\mathrm{t}}}\right)^{2}\right] \cdot d \mathrm{t}=\frac{1}{2}=0.5 \\
& \Leftrightarrow \mathrm{t}_{0}=200.34=\exp (\overline{\mathrm{t}}=5.3) \\
& \text { And } \mathrm{P}_{\mathrm{r}}\left(\mathrm{t}_{0}=200.34\right)=0.5 \\
& \text { and } \mathrm{P}_{\mathrm{m}}\left(\mathrm{t}_{0}=200.34\right) / \mathrm{i}=1-0.5=0.5
\end{aligned}
$$

So $\mathrm{P}_{\mathrm{r}}\left(\mathrm{t}_{0}\right)$ and $\mathrm{P}_{\mathrm{m}}\left(\mathrm{t}_{0}\right) / \mathrm{i}$ intersect at $(200.34,0.5)$.

Moreover, the minimum of DOK and the maximum of MChf occur at (200.34, 0.5).

So we conclude that $\mathrm{P}_{\mathrm{r}}\left(\mathrm{t}_{0}\right), \mathrm{P}_{\mathrm{m}}\left(\mathrm{t}_{0}\right) / \mathrm{i}$, DOK and MChf all intersect at (200.34, 0.5) (Fig. 23-25).

\subsubsection{The EKA Parameters Analysis in the Prognostic of Degradation:}

In this case, we note from the figure below that the DOK is maximum $(\mathrm{DOK}=1)$ when MChf is minimum $(\mathrm{MChf}=0)$ (points $\mathrm{J} \& \mathrm{~L}$ ). Afterward, the magnitude of the chaotic factor MChf starts to increase with the decrease of DOK until it reaches 0.5 at $t_{0}=200.34$ (point $\mathrm{K}$ ). Since the real probability $\mathrm{P}_{\mathrm{r}}$ is a lognormal distribution it will intersect with DOK at the point $(200.34,0.5)$ (point K). With the increase of $t_{0}$, Chf and MChf return to zero and the DOK returns to 1 where we reach total damage $(\mathrm{D}=1)$ and hence the total certain failure $\left(\mathrm{P}_{\mathrm{r}}=1\right)$ of the system (point $\mathrm{L}$ ). We note that the point $\mathrm{K}$ is no more at the middle of DOK since the lognormal distribution is not symmetric.

At each instant $t_{0}$, the remaining useful lifetime $\operatorname{RUL}\left(\mathrm{t}_{0}\right)$ is certainly predicted in the complex set $\mathrm{C}$ with $\mathrm{Pc}$ maintained as equal to one through a continuous compensation between DOK and Chf. This compensation is from instant $t_{0}=0$ where $D\left(t_{0}\right)=0$ until the failure instant $t_{N}$ where $D\left(t_{N}\right)=1$ (Fig. 23). 
Abdo Abou Jaoude / Journal of Mathematics and Statistics 10 (1): 1-24, 2014

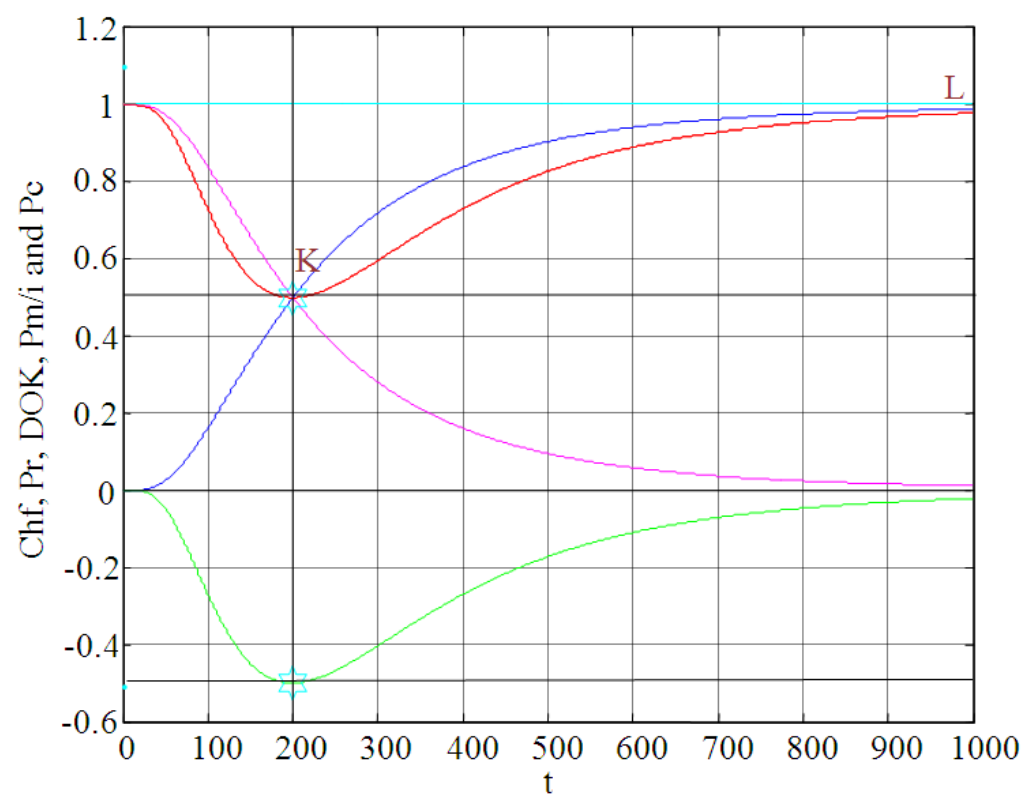

---- Chf: Chaotic factor

---- Pr: Real probability

---- DOK: Degree of our knowledge

---- Pm/i: Complementary probability

--- Pc: Probability in the set $\mathrm{C}$

Fig. 23. EKA parameters in log-normal probability distribution

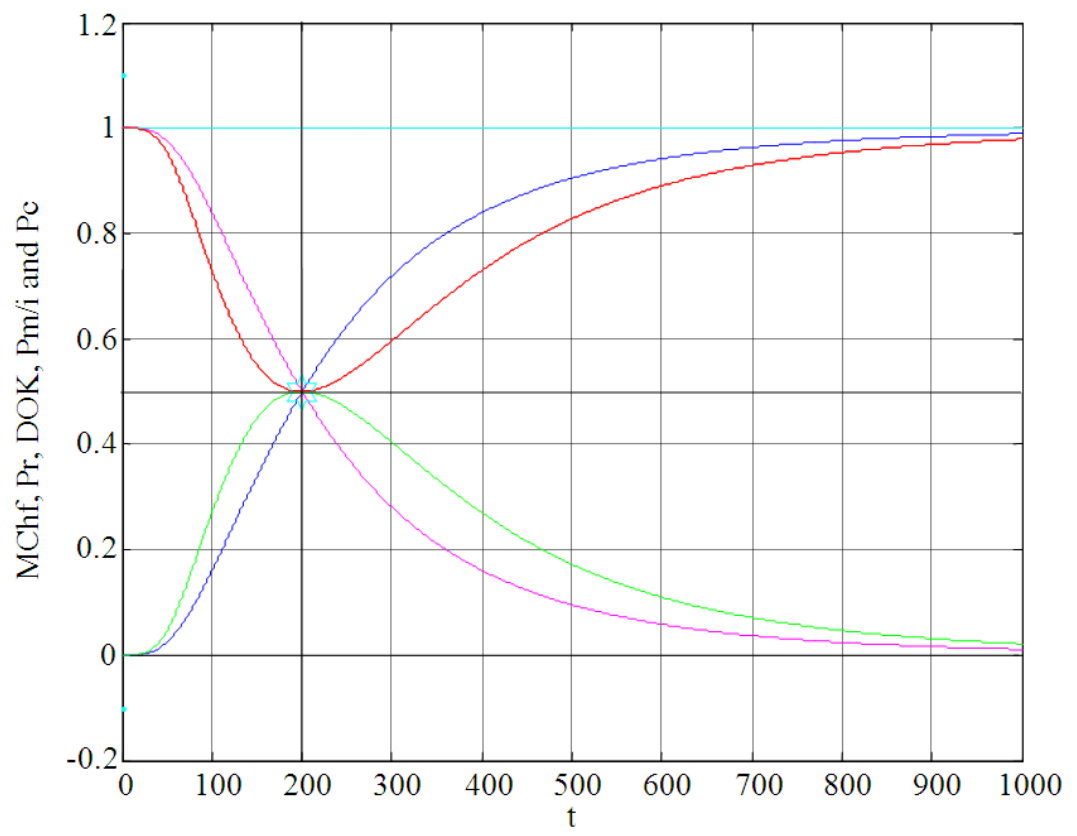

Fig. 24. EKA parameters in log-normal probability distribution 


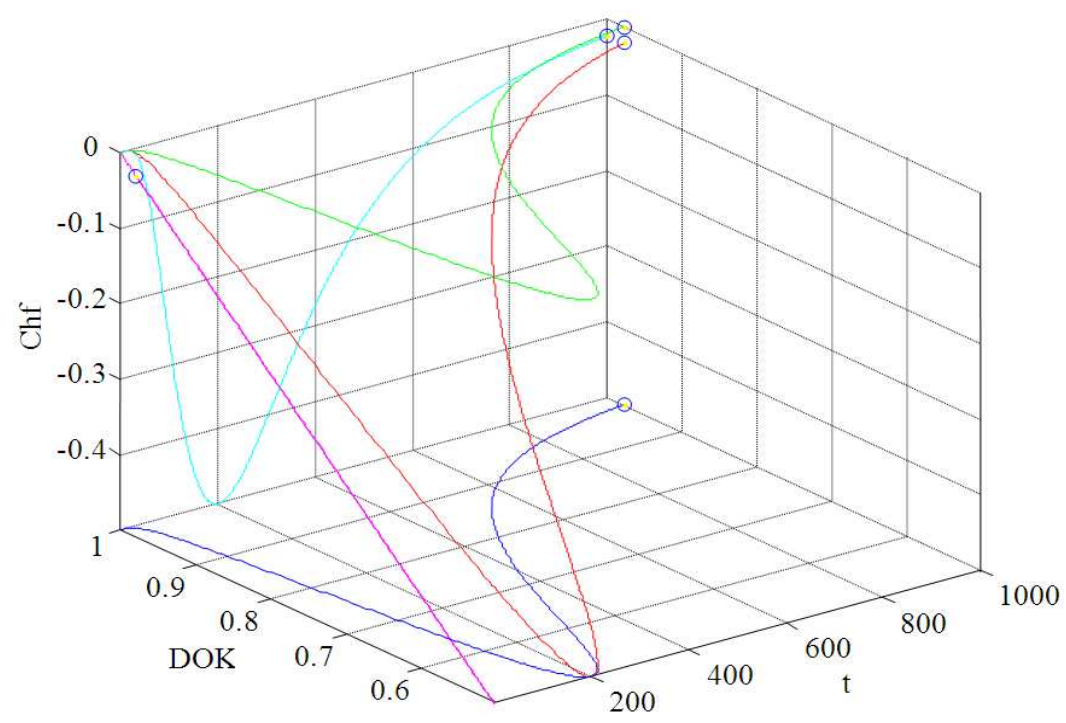

Fig. 25. DOK and Chf in terms of $t$ and of each other in log-normal probability distribution

\section{CONCLUSION}

In this study I applied the theory of Extended Kolmogorov Axioms to different probability distributions: the uniform, the logarithmic, the power, the exponential, the normal and the lognormal cumulative probability distributions. In addition, I established a tight link between the new theory and degradation or the remaining useful lifetime. Hence, I developed the theory of "Complex Probability" beyond the scope of the previous first and second paper on this topic. As it was proved and illustrated, when the degradation index is 0 or 1 and correspondingly the RUL is $t_{\mathrm{N}}$ or 0 then the Degree of Our Knowledge (DOK) is one and the chaotic factor (Chf and MChf) is 0 since the state of the system is totally known. During the process of degradation $(0<\mathrm{D}<1)$ we have: $0.5<\mathrm{DOK}<1,-0.5<\mathrm{Chf}<0$ and $0<\mathrm{MChf}<0.5$. Notice that during the whole process of degradation we have $\mathrm{Pc}=\mathrm{DOK}-\mathrm{Chf}=\mathrm{DOK}+$ $\operatorname{MChf}=1$, that means that the phenomenon which seems to be random and stochastic in $\mathrm{R}$ is now deterministic and certain in $\mathrm{C}=\mathrm{R}+\mathrm{M}$ and this after adding to $\mathrm{R}$ the contributions of $\mathrm{M}$ and hence after subtracting the chaotic factor from the degree of our knowledge. Moreover, for each value of an instant $t_{0}$, I have determined its corresponding probability of survival or of the remaining useful lifetime $\operatorname{RUL}\left(\mathrm{t}_{0}\right)=$ $t_{N}-t_{0}$. In other words, at each instant $t_{0}, \operatorname{RUL}\left(t_{0}\right)$ is certainly predicted in the complex set $\mathrm{C}$ with $\mathrm{Pc}$ maintained as equal to one through a continuous compensation between DOK and Chf. This compensation is from instant $t_{0}=0$ where $D\left(t_{0}\right)=0$ until the failure instant $t_{N}$ where $D\left(t_{N}\right)=1$. Furthermore, using all these graphs illustrated throughout the whole paper, we can visualize and quantify both the system chaos (Chf and MChf) and the system certain knowledge (DOK and Pc). This is certainly very interesting and fruitful and shows once again the benefits of extending Kolmogorov's axioms and thus the originality and usefulness of this new field in mathematics that can be called verily: "The Complex Probability and Statistics Paradigm".

\section{REFERENCES}

Abou Jaoude, A., 2005. Computer simulation of monte carlo methods and random phenomena. Ph.D. Thesis, Bircham International University.

Abou Jaoude, A., 2007. Analysis and algorithms for the statistical and stochastic paradigm. Ph.D. Thesis, Bircham International University.

Abou Jaoude, A., 2013. The complex statistics paradigm and the law of large numbers. J. Math. Stat., 9: 289304. 10.3844/jmssp.2013.289.304

Abou Jaoude, A., K. El-Tawil and S. Kadry, 2010. Prediction in complex dimension using kolmogorov's set of axioms. J. Math. Stat., 6: 116124. 10.3844/jmssp.2010.116.124 
Bell, E.T., 1992. The Development of Mathematics. 1st Edn., Courier Dover Publications, New York, ISBN10: 0486152286, pp: 637.

Benton, W., 1996. Encyclopedia Britannica. 1st Edn., Encyclopedia Britannica Inc., Chicago.

Boursin, J.L., 1986. Les Structures du Hasard. 1st Edn., Seuil, ISBN-10: 2020092352, pp: 186.

Chen, W., D.D. Kee and P.N. Kaloni, 1997. Advanced Mathematics for Applied and Pure Sciences. 1st Edn., Gordon and Breach, Amsterdam, ISBN-10: 905699607X, pp: 880.

Cheney, E.W. and D.R. Kincaid, 2004. Numerical Mathematics and Computing. 5th Edn., ThomsonBrooks/Cole, Belmont, ISBN-10: 0534389937, pp: 817.

Dacunha-Castelle, D., 1999. Chemins de L'aléatoire: le Hasard et le Risque Dans la Société Moderne. 1st Edn., Flammarion, Paris, ISBN-10: 2080814400, pp: 265.

Dalmedico Dahan, A. and J. Peiffer, 1986. Une Histoire des Mathématiques: Routes et Dédales. 2nd Edn., Edition du Seuil, ISBN-10: 2020091380, pp: 308.

Dalmédico Dahan, A., P. Arnoux and J.L. Chabert, 1992. Chaos et Déterminisme. 1st Edn., Ed. du Seuil, Paris, ISBN-10: 2020151820, pp: 414.

Ducrocq, A. and A. Warusfel, 2004. Les Mathematiques, Plaisir et Nécessité. 1st Eds., Seuil, Paris, ISBN-10: 2020612615, pp: 296.

Ekeland, I., 1991. Au Hasard: la Chance, la Science, et le Monde. 1st Edn., Editions du Seuil, Paris, ISBN-10: 2020128772, pp: 198.

Feller, W., 1968. An Introduction to Probability Theory and Its Applications. 3rd Edn., Wiley, New York.

Finney, Weir and Giordano, 2004. Thomas' Calculus. 10th Edn., Addison Wesley Longman. United States of America.

Gentle, J.E., 2003. Random Number Generation and Monte Carlo Methods. 1st Edn., Springer, New York, ISBN-10: 0387001786, pp: 381.

Gerald, F.C. and O.P. Wheatley, 1999. Applied Numerical Analysis. 6th Edn., Addison Wesley, Reading, ISBN-10: 0201474352, pp: 698.

Gleick, J., 1997. Chaos: Making a New Science. 1st Edn., Vintage, London, ISBN-10: 0749386061, pp: 352.

Greene, B., 2000. The Elegant Universe. 1st Edn., Demco Media, ISBN-10: 0606252657, pp: 447.

Greene, B., 2004. The Fabric of the Cosmos: Space, Time and the Texture of Reality. 1st Edn., Allen Lane, Penguin Books, ISBN-10: 0713996773, pp: 569.

Guillen, M., 1995. Initiation aux Mathématiques. 1st Edn., Albin Michel.
Gullberg, J., 1997. Mathematics: From the Birth of Numbers. 1st Edn., W.W. Norton, New York, ISBN10: 039304002X, pp: 1093.

Kuhn, S.T., 1996. The Structure of Scientific Revolutions. 3rd Edn., University of Chicago Press. Chicago, ISBN-10: 0226458083, pp: 212.

Liu, J.S., 2001. Monte Carlo Strategies in Scientific Computing. 1st Edn., Springer, New York, ISBN10: 0387952306, pp: 343.

Mandelbrot, B., 1997. Fractales, Hasard et Finances. 1st Edn., Flammarion, Paris.

Montgomery, C.D. and C.G. Runger, 2005. Applied Statistics and Probability for Engineers. 3rd Edn., John Wiley and Sons, New York, ISBN-10: 0471735566, pp: 720.

Mũller, X., 2005. Mathématiques: l'ordinateur aura bientot le dernier mot. Science et Vie.

Orluc, L. and H. Poirier, 2005. Génération fractale, les enfants de mandelbrot. Science et Vie.

Poincaré, H., 1968. La science et l'Hypothèse. 1st Edn., Flammarion, Paris, pp: 252.

Prigogine, I. and I. Stengers, 1992. Entre le Temps et l'Eternité. 1st Edn., Flammarion, Paris, ISBN-10: 2080812629, pp: 222.

Prigogine, I., 1997. The End of Certainty. 1st Edn., Free Press, New York, ISBN-10: 0684837056, pp: 228.

Robert, C. and G. Casella, 2010. Monte Carlo Statistical Methods. 2nd Edn., Springer, New York, ISBN-10: 1441919392, pp: 645.

Science et Vie, 1999. Le Mystère des Mathématiques.

Srinivasan, S.K. and K.M. Mehata, 1978. Stochastic Processes. 1st Edn., McGraw-Hill, New Delhi, ISBN-10: 0070966125, pp: 388.

Stewart, I., 1996. From Here to Infinity. 1st Edn., Oxford University Press, New York, ISBN-10: 0192832026, pp: 310.

Stewart, I., 2002. Does God Play Dice?: The New Mathematics of Chaos. 2nd Edn., Wiley, Oxford, ISBN-10: 0631232516, pp: 416.

Van Kampen, N.G., 2007. Stochastic Processes in Physics and Chemistry. 3rd Edn., North Holland, ISBN-10: 0444529659, pp: 464.

Walpole, R.E., 2002. Probability and Statistics for Engineers and Scientists. 7th Edn., Prentice Hall, Upper Saddle River, ISBN-10: 0130415294, pp: 730.

Weinberg, S., 1992. Dreams of a Final Theory. 1st Edn., Pantheon, New York, ISBN-10: 0679419233, pp: 334. 